\title{
2D PWV monitoring of a wide and orographically complex area with a low dense GNSS network
}

\author{
Ilaria Ferrando* $\mathbb{0}$, Bianca Federici and Domenico Sguerso
}

\begin{abstract}
This study presents an innovative procedure to monitor the precipitable water vapor (PWV) content of a wide and orographically complex area with low-density networks. The procedure, termed G4M (global navigation satellite system, GNSS, for Meteorology), has been developed in a geographic information system (GIS) environment using the free and open source GRASS GIS software (https://grass.osgeo.org). The G4M input data are zenith total delay estimates obtained from GNSS permanent stations network adjustment and pressure $(P)$ and temperature ( $T$ ) observations using existing infrastructure networks with different geographic distributions in the study area. In spite of the wide sensor distribution, the procedure produces 2D maps with high spatiotemporal resolution (up to $250 \mathrm{~m}$ and $6 \mathrm{~min}$ ) based on a simplified mathematical model including data interpolation, which was conceived by the authors to describe the atmosphere's physics. In addition to PWV maps, the procedure provides $\triangle P W V$ and heterogeneity index maps: the former represents PWV variations with respect to a "calm" moment, which are useful for monitoring the PWV evolution; and the latter are promising indicators to localize severe meteorological events in time and space. This innovative procedure is compared with meteorological simulations in this paper; in addition, an application to a severe event that occurred in Genoa (Italy) is presented.
\end{abstract}

Keywords: Global navigation satellite system (GNSS), Zenith total delay (ZTD), Precipitable water vapor (PWV), Severe meteorological event monitoring, Meteorological simulation

\section{Introduction}

It is widely known that the positioning precision determined by global navigation satellite system (GNSS) observations is affected by different sources of bias because of structural and nonstructural issues. One of the main biases is due to ionospheric and tropospheric refraction during the crossing of the atmosphere by the electromagnetic GNSS signal. The ionospheric effect can be eliminated by combination of the L1 and L2 phases for double-frequency receivers; it can be modeled for singlefrequency receivers. In contrast, tropospheric bias is frequency-independent and cannot be reduced by means of any combination. The tropospheric effect produces a bias in each satellite receiver observation that can be related

*Correspondence: ilaria.ferrando@edu.unige.it Department of Civil, Chemical and Environmental Engineering, University of Genoa, Via Montallegro 1, 16145 Genoa, Italy to the so-called zenith total delay (ZTD). The ZTD can be computed in the zenith direction above the GNSS station using an appropriate mapping function. The estimation of the ZTD helps to enhance the positioning precision and interpret severe meteorological events, as demonstrated in previous studies (Bouma and Stoew 2001; De Pondeca and Zou 2001; Basili et al. 2003; Bock et al. 2008; Boniface et al. 2009; Bennitt and Jupp 2012; Sguerso et al. 2013, 2015; Tsuda et al. 2013).

Considering the atmosphere as a biphasic fluid composed of a mix of dry and wet gases, the ZTD may be split into two components: zenith hydrostatic delay (ZHD) and zenith wet delay (ZWD). The ZHD is due to the mix of dry gases in the atmosphere and can be modeled by means of consolidated relations involving the latitude and height of the GNSS station and atmospheric pressure measured in its proximity. The ZWD is due to water vapor refractivity caused by the dipole moment of 
water vapor molecules and is typically obtained from the difference between ZTD and ZHD (Bevis et al. 1992).

The ZWD is closely related to precipitable water vapor (PWV) through the temperature (Bevis et al. 1992). The PWV represents the maximum amount of condensable water contained in an imaginary unitary base column, which extends from the GNSS receiver height to the upper limit of the troposphere. Under conditions triggering water vapor condensation, the PWV can be considered as the upper limit of precipitable water.

This work presents an innovative procedure, termed GNSS for Meteorology (G4M), to monitor the PWV content on a wide and orographically complex area in space and time using ZTD estimates obtained from GNSS permanent station (PS) network adjustment and pressure $(P)$ and temperature $(T)$ observations.

The strength and originality of the proposed approach is the use of existing infrastructure, both for the GNSS and meteorological sensors. The distribution of such networks differs; they are typically not colocated and spread over the study area.

A simplified mathematical model including data interpolation, conceived by the authors (under evaluation for a patent), describing the atmospheric $P$ and $T$ distribution is introduced. Based on this model, 2D maps with high spatiotemporal resolution are produced, in spite of the wide sensor distribution.

Finally, with the aim of interpreting severe meteorological events, a heterogeneity index (HI) is defined and applied to PWV maps. Based on the good correspondence of the HI with the location of the intense events, it is proposed to be their precursor index. The potential of the G4M procedure is high due to its independence from meteorological models, the high adaptability to different network configurations, and the possibility of its automation for near real-time applications.

The paper is organized as follows: after an overview of the state of the art in "GNSS meteorology: state of the art" section and the introduction of the Bevis equations in "GNSS meteorology: Bevis equations" section, the G4M procedure is described, applied, and validated based on an area at the French-Italian border in "The innovative G4M procedure" section. The application of the G4M procedure to a severe meteorological event is described and discussed in "Test case: the severe event in Genoa (Italy) on November 4, 2011" section using a posteriori and simulated near real-time approaches. Lastly, conclusions and future developments are reported in "Conclusions and future perspectives" section.

\section{GNSS meteorology: state of the art}

The use of GNSS for meteorological purposes has become quite popular over the last few decades because of its advantages such as high accuracy, all-weather operation, high temporal resolution, and complementarity with other observation systems (e.g., radiosondes, water vapor radiometers, and environmental satellites). Existing networks (not specifically designed for meteorological purposes) and specifically designed dense GNSS networks have been used for monitoring the distribution of water vapor in the atmosphere, with particular reference to its lower layer, that is, the troposphere. At least three different approaches have been applied: (1) investigation of the vertical column over a single station (Rocken et al. 1997), (2) exploitation of existing national GNSS networks (Seko et al. 2007; Inoue and Inoue 2007), and (3) implementation of specifically designed dense and hyperdense GNSS networks (Zhang et al. 2008; Realini et al. 2012; Sato et al. 2013; Tsuda et al. 2013; Oigawa et al. 2015). In all aforementioned studies, which are surely not exhaustive, the water vapor content was monitored to support weather forecasting, which is useful for interpreting severe meteorological events.

The main purpose of all aforementioned studies was to improve the knowledge about the water vapor distribution, which remains one of the most poorly characterized meteorological parameters.

With respect to the third approach, one of the first GNSS networks used to analyze moisture variations associated with moist convection is the Japanese nationwide GNSS network, GEONET, which has been introduced in Shoji et al. (2000, 2004). The GEONET network includes more than 1300 stations throughout Japan, with an average spacing of approximately $20 \mathrm{~km}$. The main purpose of the network is the monitoring of crustal deformation; however, it has a high potential as a meteorological sensor (Shoji 2009) and was used in several meteorological applications (e.g., Seko et al. 2007; Inoue and Inoue 2007). The GEONET-derived PWV has been used for mesoscale analyses since 2009.

In addition to the use of existing national GNSS networks, dense and hyperdense GNSS networks, especially dedicated to meteorological purposes, were designed and installed. Zhang et al. (2008) designed a mixed singleand double-frequency GNSS network with $\sim 5$ - to 10-km spacing between the stations to support the weather forecasting in the metropolitan area of Beijing (China). Realini et al. (2012) and Sato et al. (2013) installed a network of 17 dual-frequency GNSS stations, specifically designed for high-resolution PWV measurements. The network has a horizontal spacing of 1-2 km, covers an area of approximately $10 \times 6 \mathrm{~km}^{2}$, and is located near the Uji Campus of Kyoto University (Japan). The network was used for several different scientific applications:

- characterization of the temporal and spatial PWV variability at a local scale using 2D maps of GNSSderived PWV (Realini et al. 2012); 
- validation of GNSS-derived PWV with respect to radiosonde/radiometer PWV (Sato et al. 2013);

- feasibility study of extending the GNSS network to the entire urban area in high resolution by introducing several hundred low-cost and single-frequency receivers (Tsuda et al. 2013);

- exploitation of the network to study the correlation between PWV fluctuations and the occurrence of intense rain by focusing on heavy rainfall events (Oigawa et al. 2015).

An element of innovation in this field has been introduced by Sguerso et al. (2013) who proposed the use of several existing regional, national, and international GNSS PSs to estimate the ZTD for climatological applications and to monitor the PWV content of a wide and orographically complex area.

\section{GNSS meteorology: Bevis equations}

The local PWV value can be evaluated through ZTD estimates of a GNSS PS and colocated ground-based measurements of $P$ and $T$ by applying the equations proposed by Bevis et al. (1992):

$$
\mathrm{ZHD}=\frac{(2.2779 \pm 0.0024) \cdot P}{1-0.00266 \cdot \cos (2 \varphi)-0.00028 \cdot H},
$$

where $P$ is the pressure in $\mathrm{hPa}, \phi$ is the latitude, and $H$ is the ellipsoidic height in $\mathrm{km}$;

$$
\mathrm{ZWD}=\mathrm{ZTD}-\mathrm{ZHD}
$$

and

$$
\mathrm{PWV}=\Pi \cdot \mathrm{ZWD},
$$

where

$$
\Pi=\frac{10^{6}}{R_{v} \cdot \rho} \cdot\left(k_{2}^{\prime}+\frac{k_{3}}{T_{m}}\right)^{-1}
$$

The coefficients in Eq. (4) are:

$$
\begin{aligned}
& R_{v}=461.70 \quad\left(\frac{\mathrm{J}}{\mathrm{kg} \mathrm{K}}\right) \\
& \rho=1000 \quad\left(\frac{\mathrm{kg}}{\mathrm{m}^{3}}\right) \\
& k_{2}^{\prime}=17 \pm 10 \quad\left(\frac{\mathrm{K}}{\mathrm{hPa}}\right) \\
& k_{3}=(3.776 \pm 0.03) \cdot 10^{5} \quad\left(\frac{\mathrm{K}^{2}}{\mathrm{hPa}}\right) \\
& T_{m}=\frac{\int \frac{P_{v}}{T}}{\int \frac{P_{v}}{T^{2}}} \cong 70.2+0.72 \cdot T \quad(\mathrm{~K})
\end{aligned}
$$

The PWV computation for a single location using these equations can be easily implemented in a geographic information system (GIS) environment to analyze the spatial distribution of the computed data.

However, a procedure that spatially combines such data to produce PWV maps is necessary if the ZTD, $P$, and $T$ data are not colocated.

\section{The innovative G4M procedure}

The innovative G4M procedure to monitor the PWV content of a wide and orographically complex area by analyzing independently located GNSS and $P$ and $T$ observations originating from existing low-density networks is described here. The procedure has been developed in a GIS environment using the free and open source GRASS GIS software.

The G4M input data are ZTD estimates obtained from PSs network adjustment and $P$ and $T$ observations derived from meteorological sensor networks. Such networks are usually characterized by a low spatial density and different spacing across the territory (e.g., the mean spacing of regional GNSS PSs is $\sim 40 \mathrm{~km}$, while that of worldwide meteorological stations, such as the one integrated in the NOAA ${ }^{1}$ database, is $\sim 150 \mathrm{~km}$ ) and are often not colocated. In spite of the wide distribution of the sensors, the procedure yields $2 \mathrm{D}$ maps with high spatiotemporal resolution (up to $250 \mathrm{~m}$ and $6 \mathrm{~min}$ ).

The strength and originality of the procedure are based on:

- the use of existing GNSS and meteorological infrastructure (not necessarily colocated);

- the ability to produce high-resolution 2D PWV maps, even from such sparse input data;

- the high adaptability of the procedure to different network configurations;

- the introduction of a simplified mathematical model including data interpolation, conceived by the authors (under evaluation for a patent), to describe the atmospheric $P$ and $T$ behavior and improve the interpolation of $P$ and $T$ data;

- the definition of a HI, which was conceived to localize severe meteorological events in time and space;

- the independence from meteorological models;

- the automation for near real-time applications.

In the following, the procedure and its application to the area near the French-Italian border are illustrated. The GNSS PSs network and its use to estimate the ZTD values for every PS and the $P$ and $T$ networks are described in "From GNSS to ZTD estimate" and "From 
ZTD to PWV: pressure and temperature data" sections, respectively. Section "From ZTD to PWV: 2D innovative procedure" presents the G4M procedure and focuses on data interpolation, comparison, and validation using "internal" (between the different tested interpolators) and "external" (with meteorological simulations) comparisons. Finally, the HI, which was conceived to study the occurrence of severe meteorological events, is described in "An indicator of severe rainfall: heterogeneity index (HI)" section.

\section{From GNSS to ZTD estimate}

From both a climatologic and meteorological point of view, the ZTD estimates must be derived from a homogeneous adjustment of a GNSS PSs network. International and national agencies addressed the estimation of tropospheric models based on PSs network elaboration (Pacione and Vespe 2003; Yao et al. 2015). The spatial and temporal resolution of such computations, suitable for climatological or meteorological analysis over a wide area, is too low for the monitoring of an intense and localized event, which is the purpose of the authors.

The adjustment of a GNSS PSs network also represents the starting point of the G4M procedure. The GNSS data originate from 181 PSs belonging to international, national, and regional networks covering the area around the French-Italian border. The different types of existing networks include global (IGS ${ }^{2}$ Tracking Network and EUREF $^{3}$ Permanent Network), transnational $\left(\right.$ GAIN $\left.^{4}\right)$, national (France: RENAG $^{5}$ and RGP $^{6}$; Switzerland: AGNES $^{7}$; Italy: GEODAF ${ }^{8}$ and RING $^{9}$ ), and regional networks (Italy: Piemonte ${ }^{1011}$ and Liguria ${ }^{12}$ ).

The total extent of the GNSS network is depicted in Fig. 1a. The different colors represent the three subnetworks into which the GNSS network is divided according to the computational limits of the adjustment software and the decreasing station age to obtain a network geometry that is stable in time. A common set of 15 stations was included in each subnetwork to achieve a stable reference frame for the entire time span. Among these 15 stations, 13 belong to IGS and two to EUREF networks.

\footnotetext{
2 http://www.igs.org.

${ }^{3}$ http://epncb.oma.be.

${ }^{4}$ http://www.alpine-space.org.

${ }^{5}$ http://webrenag.unice.fr.

${ }^{6}$ http://rgp.ign.fr.

7 http://www.swisstopo.admin.ch.

8 http://geodaf.mt.asi.it.

9 http://ring.gm.ingv.it.

10 http://www.spingnss.it.

11 http://webgis.arpa.piemonte.it.

12 http://www.gnssliguria.it.
}

Figure $1 \mathrm{~b}$ represents a zoomed image of the FrenchItalian border area in which the PSs are denser and have an average spacing of $\sim 40 \mathrm{~km}$.

The GNSS network was analyzed through common techniques and procedures employing the GAMIT/ GLOBK software versions 10.4 and 10.6 (Herring et al. 2010, 2015). The ZTDs and gradients were calculated for each PS in the network, simultaneously with a daily positioning solution for $24-\mathrm{h}$ sessions. The following settings were implemented (see Sguerso et al. 2013, for more details):

- the troposphere was modeled using the empirical global mapping function (GMF; Boehm et al. 2006); the GMF was chosen because of its homogeneity over the climatological time span and because it is independent from weather models;

- the a priori $P$ and $T$ information for each PS was computed using the Global Pressure and Temperature (GPT) model (Boehm et al. 2007). The GPT is based on $15^{\circ} \times 15^{\circ}$ global grids of monthly mean $P$ and $T$ profiles from the European Centre for Medium-Range Weather Forecasts (ECMWF) reanalysis data for 3 years (September 1999-August 2002);

- the absolute antenna phase center was modeled using the IGS_08 model (Schmid et al. 2007);

- the ocean loading FES2004 (Lyard et al. 2006) and atmospheric loading according to Tregoning and van Dam (2005) were considered;

- the IGS final orbits were readjusted during the analysis and coherent Earth orientation parameters were used;

- when available, a priori coordinates originated from ITRF2008 (Altamimi et al. 2011) but were only loosely constrained. As already mentioned, a simultaneous daily positioning solution was estimated to guarantee the homogeneous adjustment of the parameters;

- the cutoff elevation remained fixed to the conservative value of $10^{\circ}$.

The ZTD estimates were validated using two different strategies: internal and external comparisons (see Sguerso et al. 2013, for further details).

With respect to the internal comparison, the $15 \mathrm{com}$ mon PSs of the three subnetworks were used to verify the internal consistency. Based on the analysis by Sguerso et al. (2015) for a few days, the same approach was extended to an entire year (2011), the ZTD bias and standard deviation values were approximately 1 and $2 \mathrm{~mm}$, respectively. This means that the ZTD estimates of 


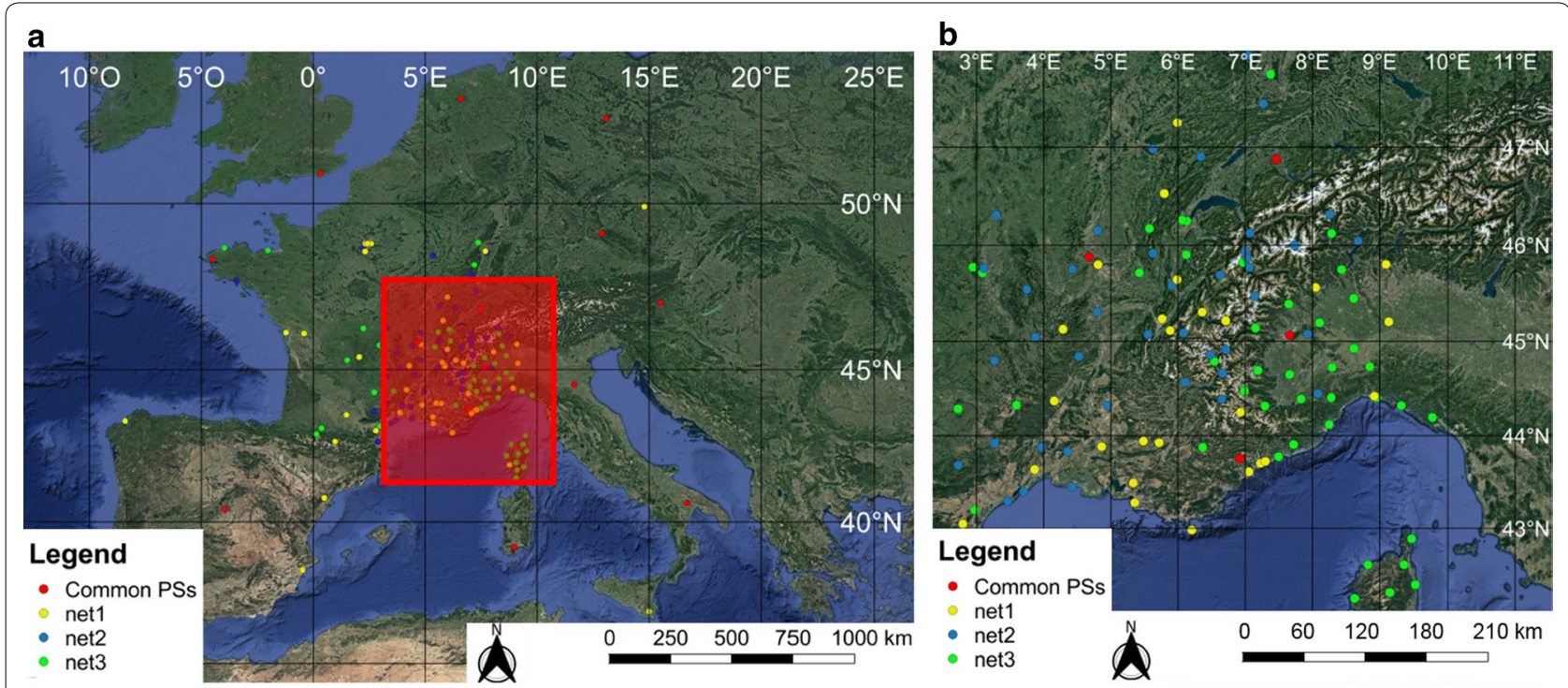

Fig. 1 Total extent of the GNSS network (a). The red rectangle corresponds to the French-Italian border region depicted in $\mathbf{b}$ in which the GNSS permanent stations (PSs) are denser. Common PSs are represented by red dots; net1, net2, and net3 are represented by yellow, blue, and green dots, respectively

the three subnetworks are coherent, with typical differences between 3 and $5 \mathrm{~mm}$.

The external comparison was obtained using the IGS official tropospheric product over an entire year (2002) for 16 PSs (Sguerso et al. 2015). Globally, the differences have a mean bias of $-3.6 \mathrm{~mm}$ and a standard deviation of $4.5 \mathrm{~mm}$. The bias could be related to different network configurations (the "regional" network is compared with the IGS global network), the lack of constraint in any a priori position of the regional network, and possible differences of the tropospheric models used for the two solutions. Additionally, the different time spans over which the two ZTD estimates were carried out ( $5 \mathrm{~min}$ for IGS solutions and $2 \mathrm{~h}$ for GAMIT solutions) should be taken into account.

A database ${ }^{13}(\mathrm{DB})$ containing 2-h ZTD estimates and 3-h horizontal North-South and East-West tropospheric gradients from 1998 to 2012 was created and made available to researchers (Sguerso et al. 2015); it was recently updated to include data up to December 2015.

\section{From ZTD to PWV: pressure and temperature data}

The $P$ and $T$ observations are necessary to derive the PWV from the ZTD estimates described in "From GNSS to ZTD estimate" section. Following the criterion of exploiting existing infrastructure, $P$ and $T$ observations were extracted from the NOAA Integrated Surface

\footnotetext{
$\overline{13} \mathrm{ftp} / / /$ renag.unice.fr//products/GPS_climatology_Sguerso_Labbouz_ Walpersdorf.
}

Database $^{14}$ (ISD), representing an archive of global historical weather and climate data. The $P$ and $T$ land-based observations were collected from sensors installed worldwide, allowing for the application of the procedure in any area of the world. The observed atmospheric variables, collected in NOAA's ISD, include the temperature, dew point, relative humidity, precipitation, wind speed and direction, visibility, atmospheric pressure, and types of weather occurrences such as hail, fog, and thunder. Data are available at sub-hourly, hourly, daily, monthly, annual, and multiannual timescales.

A selected number of $P$ and $T$ stations at the FrenchItalian border, belonging to the NOAA archive, were chosen. The $P$ and $T$ stations are not always colocated because the $P$ and $T$ are not measured at all stations and because of the occasional lack of data. Above all, they are not colocated with GNSS stations, which have a denser distribution. The average spacing of the $P$ and $T$ network is $150 \mathrm{~km}$, with a significant difference over time in case of the lack of data during the analysis of the meteorological event.

A representation of the complete $P$ and $T$ network is given in Fig. 2: $P$ and $T$ stations are depicted as red and blue dots, respectively. The black dots represent the GNSS PSs. The scale bar (m) refers to the ASTER Global Digital Elevation Model (GDEM) ${ }^{15}$ which was used as background.

\footnotetext{
${ }^{14}$ https://www.ncdc.noaa.gov/isd.

15 https://asterweb.jpl.nasa.gov/gdem.asp.
} 


\section{From ZTD to PWV: 2D innovative procedure}

The G4M procedure allows one to produce 2D PWV maps and analyze the PWV spatial and temporal evolution for a wide and orographically complex area using data measured from existing infrastructure. Because of the GIS environment, the G4M extends the equations proposed by Bevis et al. (1992) for a single location in two dimensions. The main difficulties arise for independently located and low-density input data over a wide and orographically complex area. The G4M spatially combines ZTD, $P$, and $T 1 \mathrm{D}$ data originating from networks with different locations and spacing by applying a simplified mathematical model describing the atmospheric $P$ and $T$ distributions.

A scheme of the G4M procedure is shown in Fig. 3. A ZTD 2D map is simply derived by proper interpolation of the ZTD locally estimated over the PSs network. The ZHD and ZWD 2D maps are generated by applying Eqs. (1) and (2), given the latitude and the digital terrain model (DTM) of the study area, and proper interpolation to local sparse $P$ data and improved by the simplified mathematical model. Finally, the PWV can be obtained from the ZWD by applying Eqs. (3-5) and proper interpolation to the local sparse $T$ data, improved by the simplified mathematical model. Further details are reported in "Data interpolation and validation" section.

The procedure was applied to the French-Italian border area and validated by comparing the obtained PWV maps to the fields derived from a weather forecasting model (details are given in "PWV validation using meteorological simulations" section).

The input data, already illustrated in "From GNSS to ZTD estimate" and "From ZTD to PWV: pressure and temperature data" sections and depicted in Fig. 2, were as follows:

- ZTD data from the 181-GNSS PSs network covering the French-Italian border area with an average spacing of $40 \mathrm{~km}$;

- $P$ and $T$ data from a selected number of meteorological stations of NOAA's archive covering the northwestern part of Italy and French-Italian border region with a spacing of approximately $150 \mathrm{~km}$;

- ASTER GDEM to describe the terrain topography with an original resolution of 1 arcminute corresponding to approximately $30 \mathrm{~m}$.

The G4M procedure was implemented using the free and open source software GRASS GIS ${ }^{16}$ version 6.4
(GRASS Development Team 2010), hereinafter referred to as GRASS. The GRASS software was chosen because of its high processing capacity and the possibility of creating ad hoc automatic procedures, a distinctive feature of the open source software.

\section{Data interpolation and validation}

Different tests of several interpolators implemented in GRASS were carried out to identify the most suitable interpolation technique, both for ZTD (Ferrando et al. 2017) and $P$ and $T$ (Ferrando et al. 2016). For a near real-time application of the G4M procedure, the interpolator should be fast and automatically adjustable to the different network configurations that can occur over time because of the temporary lack of data or eventual outliers.

The tested interpolators are the triangular irregular network (TIN), inverse distance weighted (IDW), regularized spline with tension (RST), ordinary kriging, and regression kriging to correlate $P$ and $T$ data with elevation.

An "internal" comparison was carried out to analyze the behavior of the interpolators with low density and without uniformly distributed data:

- on "check points": some of the observed data were excluded from the interpolation dataset and were only used to verify the results;

- along a section representative of the complex orography of the area: the profiles of different interpolated surfaces were compared to focus the attention on altimetric differences;

- through 2D difference maps among the surfaces produced by G4M to analyze the global behavior in the study area.

As described in detail in Ferrando et al. (2017), the "internal" comparison of ZTD maps shows that RST and kriging are not suitable for near real-time applications because of the required calibration of parameters. The IDW (using the 6 nearest points) shows an unreliable pattern when applied to a high spatial resolution $(\sim 250 \mathrm{~m})$ case study. The TIN reproduces a smoother interpolated surface and shows better results when comparing the observed values with the surface interpolated on the checkpoints. Moreover, the TIN interpolator seems to be the most appropriate for near real-time ZTD monitoring at high resolution because of the low computational 


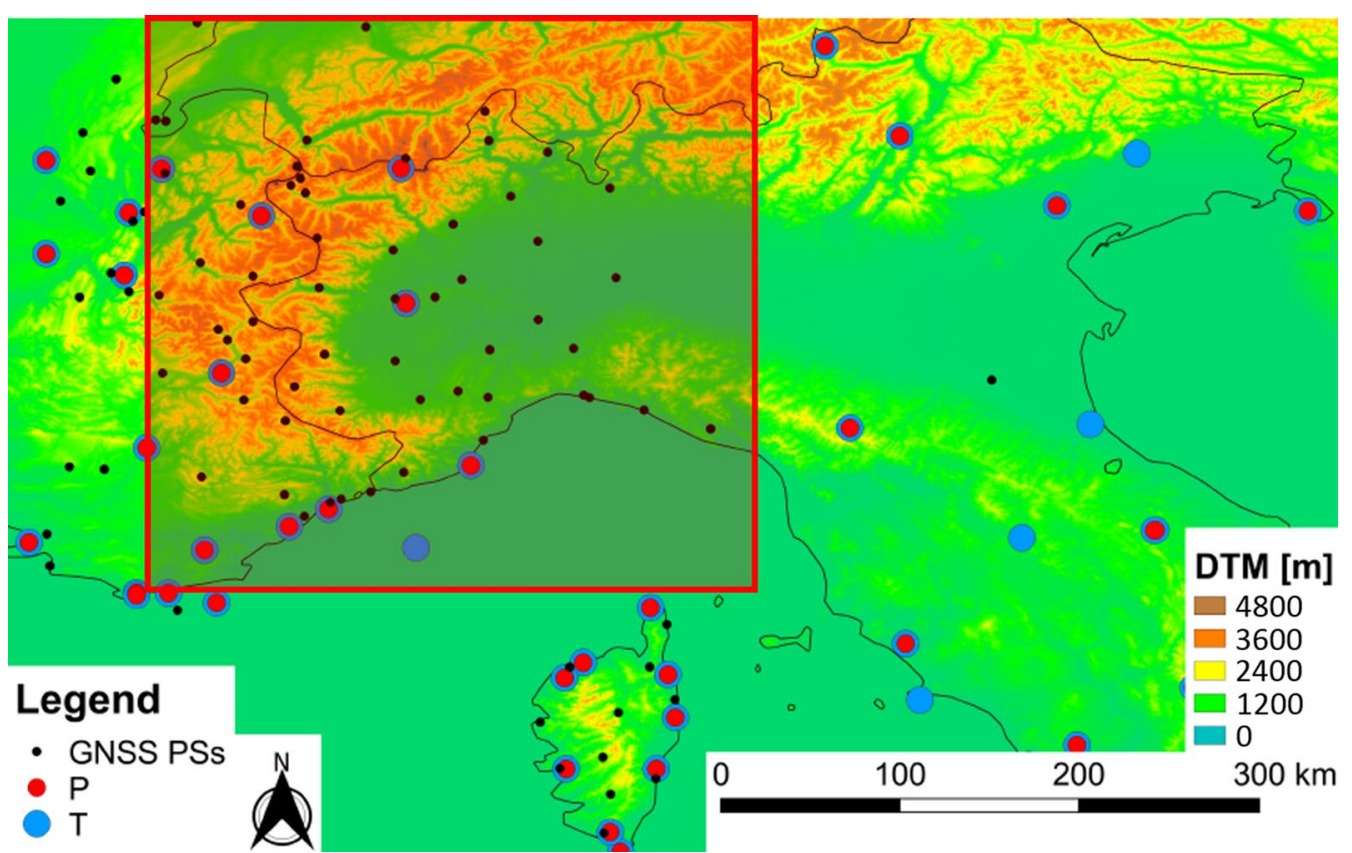

Fig. 2 Pressure $(P)$ and temperature $(T)$ stations of the NOAA database (red and blue dots). The black dots represent the GNSS PSS

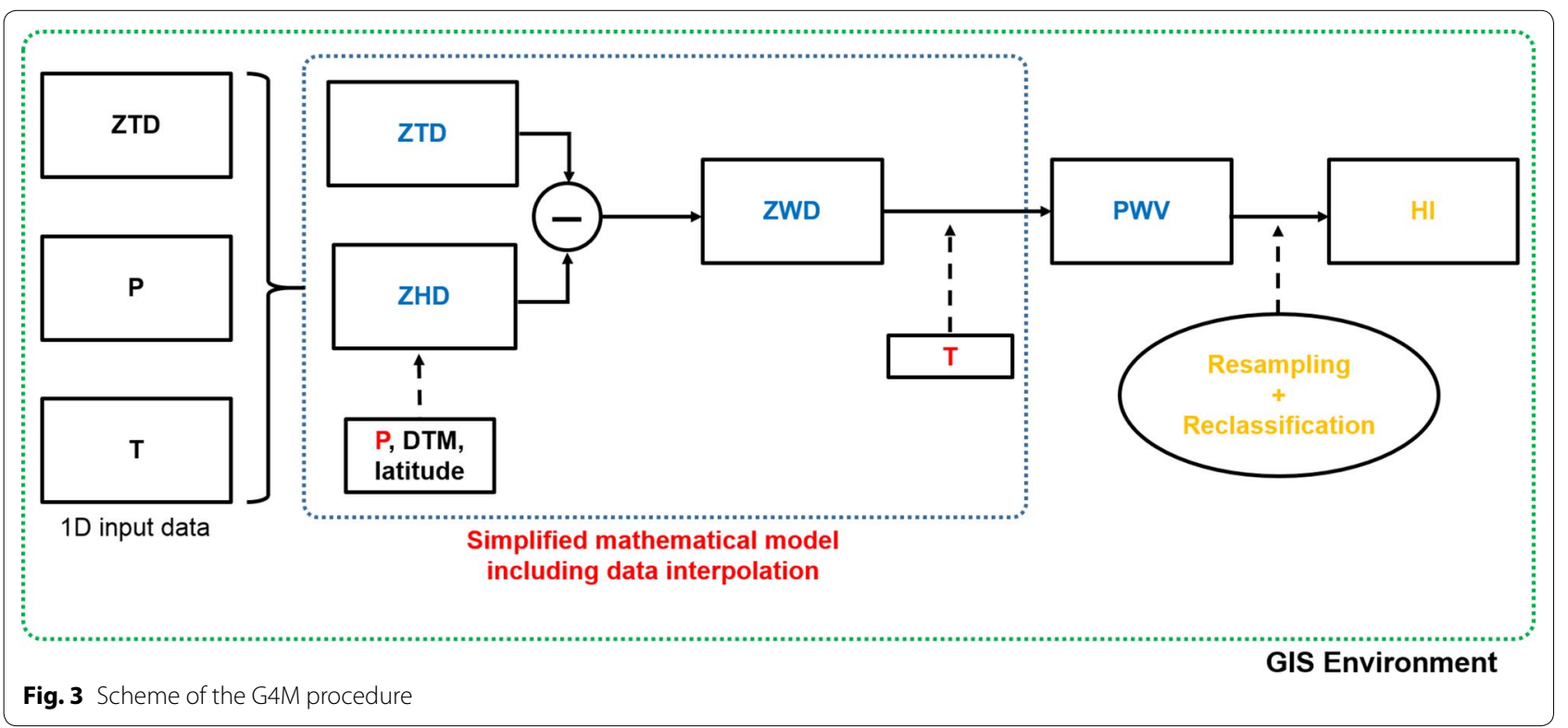

effort and high adaptability to different network configurations, without the need to define any parameter.

With respect to $P$ and $T$ fields produced by the G4M procedure, the "internal" comparison reported in Ferrando et al. (2016) showed a similar behavior for all interpolation techniques.

Subsequently, an "external" comparison was carried out. The $P$ and $T$ fields were computed by an a posteriori numerical model simulating the meteorological conditions at a certain time produced by the entire set of observed data. The simulation maps were produced using the mesoscale Weather Research and Forecasting $\left(\mathrm{WRF}^{17}\right)$ model.

${ }^{17}$ http://www.wrf-model.org. 
The simulation settings can be summarized as follows (for further details, refer to Cassola et al. 2015):

- three two-way nested computational domains in Lambert conformal conic projection covering western and central Europe, northern Italy, and the Liguria region with horizontal resolutions of $10,3.3$, and $1.1 \mathrm{~km}$, respectively;

- 35 terrain-following vertical levels with higher resolution near the surface;

- initial and boundary conditions generated from global model GFS (Environmental Modeling Center 2003) outputs with a resolution of $0.5^{\circ}$;

- 48-h WRF runs with outputs saved every hour;

- simulation starts at 00:00 UTC on November 3 and 4, 2011.

In spite of the sparse distribution of $P$ and $T$ data, the "external" comparison showed that the simplified mathematical model reliably produces 2D PWV maps, which are in good agreement with meteorological simulations. The global soundness of the TIN was confirmed, even if large differences were observed in high-altitude areas (Ferrando et al. 2016), which might have been caused by the simplification introduced by the mathematical model proposed by the authors.

\section{PWV validation using meteorological simulations}

To validate the obtained PWV maps, a comparison with the simulated PWV field derived from the WRF model (version 3.4) was performed.

The simulated PWV data have a spatial resolution of $3.3 \mathrm{~km}$ and temporal resolution of $1 \mathrm{~h}$ and include an area approximately covering northwestern Italy. For an accurate comparison, the G4M PWV maps were produced with the same resolution using the TIN interpolator.

Figure 4a and $\mathrm{b}$ depict the G4M and WRF PWV maps produced for November 4, 2011, 10:00 UTC, whereas Fig. 4c shows the PWV difference map for the G4M and WRF. The contour lines correspond to PWV values of 20 , 25, 30 and $35 \mathrm{~mm}$.

The G4M and WRF PWV vary between -22 and $126 \mathrm{~mm}$ and 6 and $37 \mathrm{~mm}$, respectively, over a wide area characterized by complex orography with elevations ranging from the sea level to $4800 \mathrm{~m}$ in the Alps. The unrealistic negative PWV values (Fig. 4a) may be due to the effect of $P$ overestimation and ZTD underestimation. In fact, $P$ is directly proportional to ZHD, which results in an inverse proportionality to PWV, and ZTD is directly proportional to PWV, as explained in Eqs. (1-5).
The PWV difference map (G4M-WRF) in Fig. 4c shows large differences in high-altitude areas (Alps and Apennines), while the two maps for flat land and the sea in Fig. $4 \mathrm{a}, \mathrm{b}$ are quite similar. This confirms the observations based on the comparison between $P$ and $T$ fields computed by the G4M and that computed by the WRF (Ferrando et al. 2016). The average and root mean square (rms) of the PWV differences are 8 and $24 \mathrm{~mm}$, respectively. These PWV differences might be due to observation and/or interpolation errors of the $P$ and $T$ fields, generated by the simplified mathematical model, and the ZTD maps, in addition to WRF uncertainties.

However, to reduce these discrepancies, differences in the PWV time with respect to a calm moment have been introduced through $\triangle \mathrm{PWV}$ maps, as discussed below.

A more detailed analysis was carried out to assess whether the encountered differences between the G4M and WRF PWV maps are significant; it followed two different approaches: (1) the analysis of the PWV time series for PSs at different elevations, and (2) the study of PWV along a section crossing complex topographic areas.

With respect to the first approach, four GNSS PSs at different elevations were chosen as follows: GENO (110 $\mathrm{m}$ a.s.l.), TORI (261 $\mathrm{m}$ a.s.l.), GRAS (1270 $\mathrm{m}$ a.s.l.), and AGNE (2300 $\mathrm{m}$ a.s.l.). At these locations, 2-h PWV values were produced using the G4M procedure for $48 \mathrm{~h}$, from November 3, 2011, 00:00 UTC to November 4, 2011, 22:00 UTC. The comparison between the G4M and WRF shows slight differences on the order of a few millimeters (Fig. 5); this highlights the correct interpretation of the PWV temporal evolution by the G4M procedure, in spite of the high influence of orography on PWV.

With respect to the second test, a section of the G4M and WRF PWV maps passing through the Alps from November 4, 2011, 10:00 UTC was studied. The position of the section and obtained PWV values are depicted in Fig. 6a. Again, a strong orographic effect is evident in the G4M PWV map.

To remove the orographic effect, the $\triangle \mathrm{PWV}$ map was introduced. The $\triangle \mathrm{PWV}$ consists of time differentiation in the PWV maps with respect to a "calm" moment when the PWV content in the atmosphere is limited. This allows the removal of the orographic effect, which is constant in time, and to highlight PWV variations. The choice of the appropriate differencing time is crucial; it should be carefully evaluated for each test case.

Figure $6 \mathrm{~b}$ reports the $\triangle \mathrm{PWV}$ trend relative to the same section of Fig. 6a. The removal of the orographic effect and a reduction in the differences between the curves, 


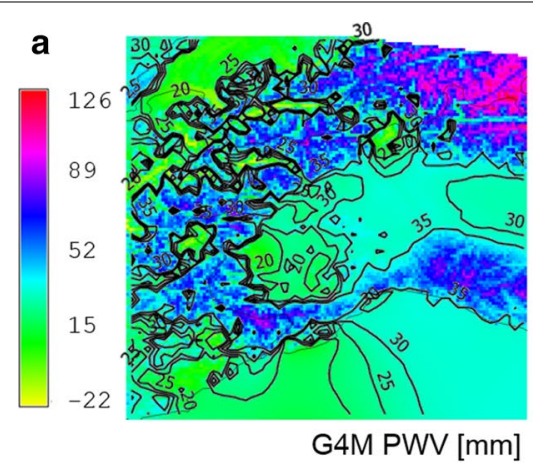

b
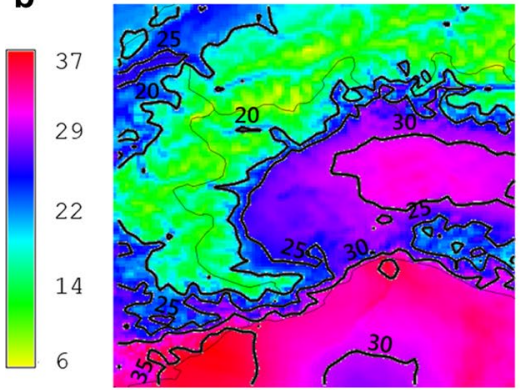

WRF PWV [mm] c

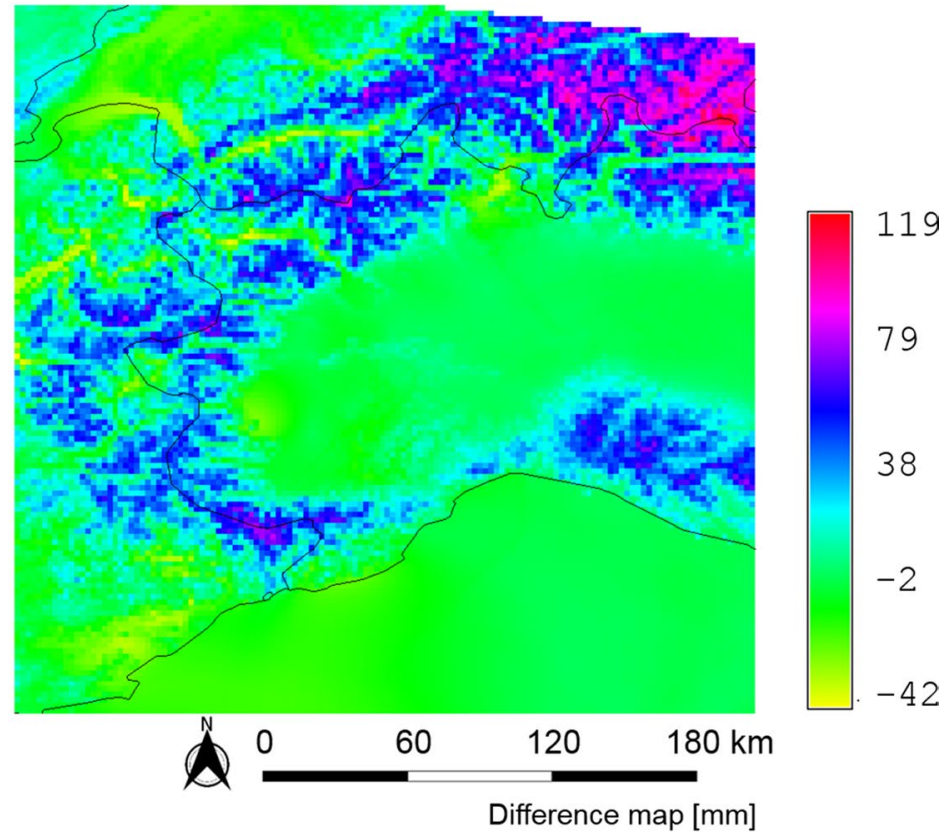

Fig. 4 PWV map from the G4M procedure (a). The orographic effect is evident in elevated areas. $\mathbf{b}$ represents the WRF PWV map and $\mathbf{c}$ depicts the PWV difference map (G4M-WRF). Large differences are mainly observed in elevated areas (Alps and Apennines). The maps refer to November 4, 2011, 10:00 UTC. The contour lines correspond to PWV values of 20, 25, 30, and $35 \mathrm{~mm}$

from more than $20 \mathrm{~mm}$ (on average) to approximately $2-3 \mathrm{~mm}$, are evident.

The same effect can be globally observed in the entire study area by creating a difference map of the G4M and WRF $\triangle$ PWV maps, as shown in Fig. 7c. The $\triangle$ PWV maps from G4M and WRF are depicted in Fig. 7a, b. In spite of the differentiation in time, several differences between the two $\triangle \mathrm{PWV}$ maps are visible, but a substantial reduction with respect to the values reported in Fig. 4 can be observed. The $\triangle \mathrm{PWV}$ differences range from -17 to $6 \mathrm{~mm}$, with a mean value of $-1 \mathrm{~mm}$ and standard deviation of $2.8 \mathrm{~mm}$.

\section{An indicator of severe rainfall: heterogeneity index $(\mathrm{HI})$}

The previously described G4M procedure is capable of producing maps for monitoring the PWV content in the atmosphere and its evolution in space and time, even during intense meteorological events. However, overcoming a threshold of PWV is not sufficient to state that a severe event will occur.

To identify remarkable PWV evolution features, which potentially precede severe meteorological events and can be used to locate them, the spatial $\triangle P W V$ variability was analyzed. Nevertheless, the $\triangle \mathrm{PWV}$ map does not help in defining where a severe event could take place.
An example is reported in Fig. 8a (relative to November 4, 2011, 10:00 UTC), where a severe event occurred in circle 1 and no rain occurred in circle 2, although both locations are characterized by a high $\triangle \mathrm{PWV}$. Hourly cumulated rainfall histograms obtained from rain gauges on November 4, 2011 are reported in Fig. 9 (circles 1 and 2 on the right and left, respectively). A more detailed description of the meteorological event is reported in the following "Test case: the severe event in Genoa (Italy) on November 4, 2011" section.

To localize intense meteorological events in time and space, an index accounting for the spatial $\triangle \mathrm{PWV}$ variability, the HI, has been conceived by the authors. The index represents the $\triangle \mathrm{PWV}$ "block standard deviation" obtained by resampling of the $\triangle \mathrm{PWV}$ maps to a coarser grid and computing the value of the standard deviation. Figure 10 shows a scheme for spatial HI resampling, assuming an original $\triangle \mathrm{PWV}$ map resolution of $250 \mathrm{~m}$ and a four times coarser HI map resolution with a grid size of $1 \mathrm{~km}$. Each pixel of the HI map represents the empirical standard deviation of the 16 included $\triangle \mathrm{PWV}$ map pixels.

For the present case study, several tests were carried out (different grid sizes: 1,3 , and $10 \mathrm{~km}$ ) to verify the most appropriate $\mathrm{HI}$ resolution. While the $10-\mathrm{km}$ grid 

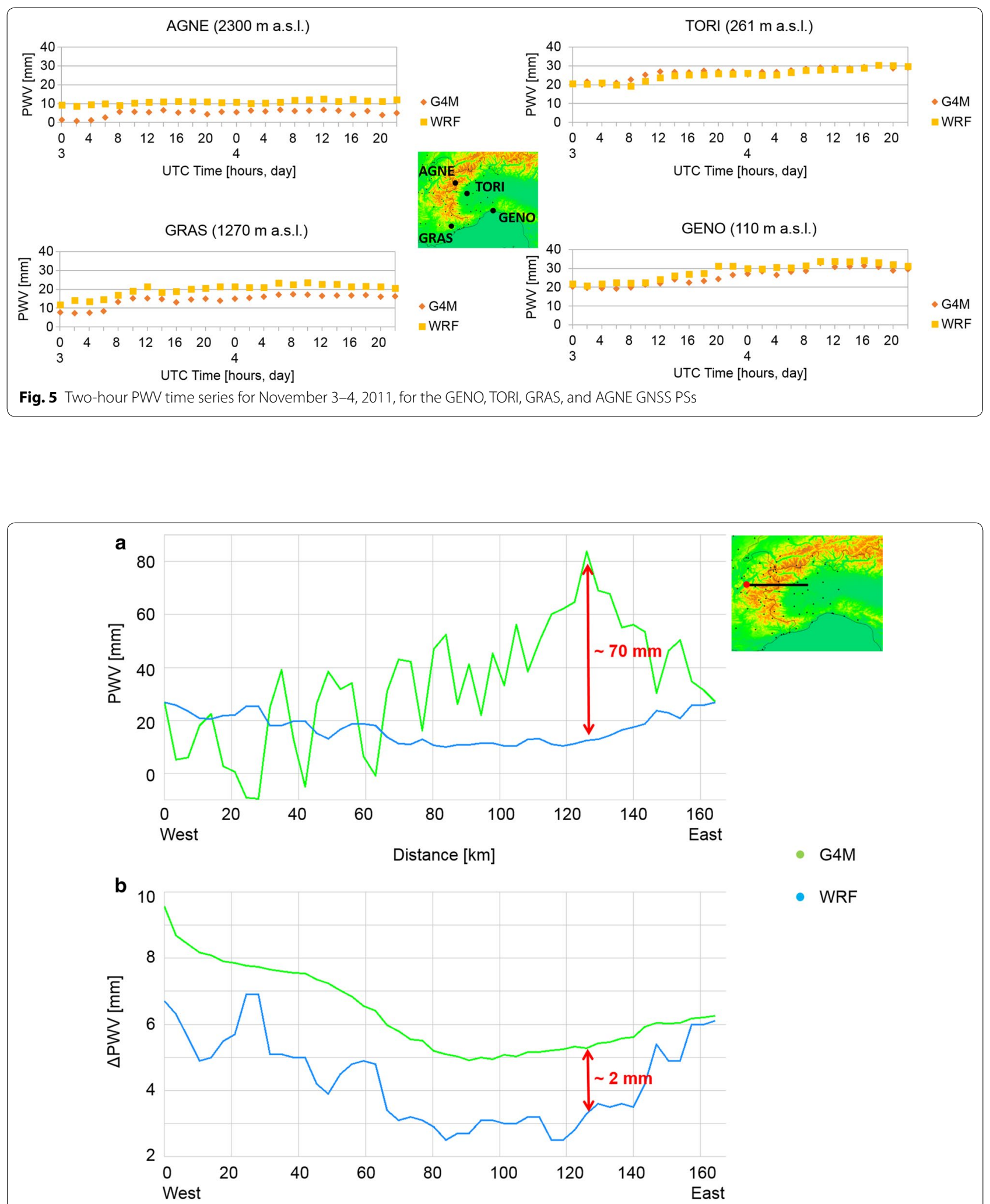

- G4M

- WRF

Distance $[\mathrm{km}]$

Fig. 6 PWV (a) and $\triangle P W V(\mathbf{b})$ values for the G4M (green) and WRF (blue). The orographic effect was successfully removed from the $\triangle P W V$ graph. The position of the section is depicted in the top right of the figure. The $x$-axis displays the distance in kilometers, from the start of the section (red dot) from west to east; the $y$-axis shows the PWV and $\triangle P W V$ values 

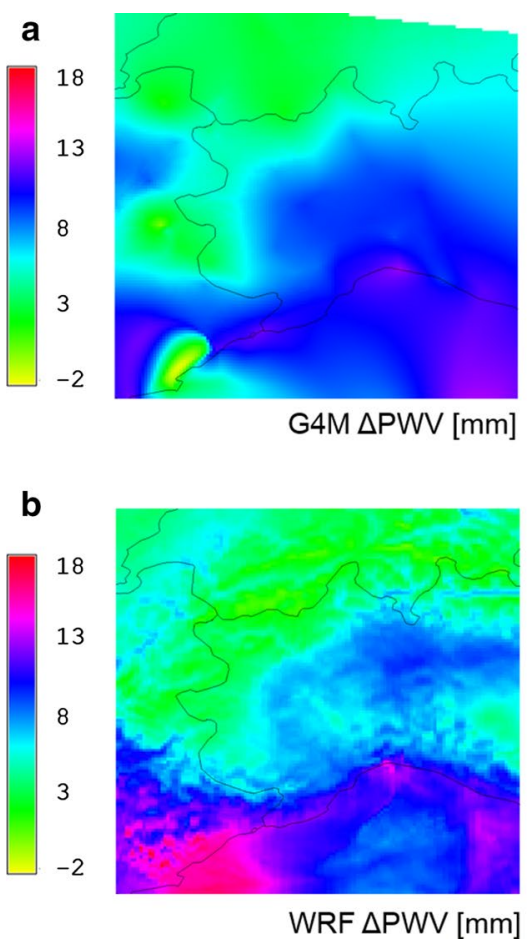

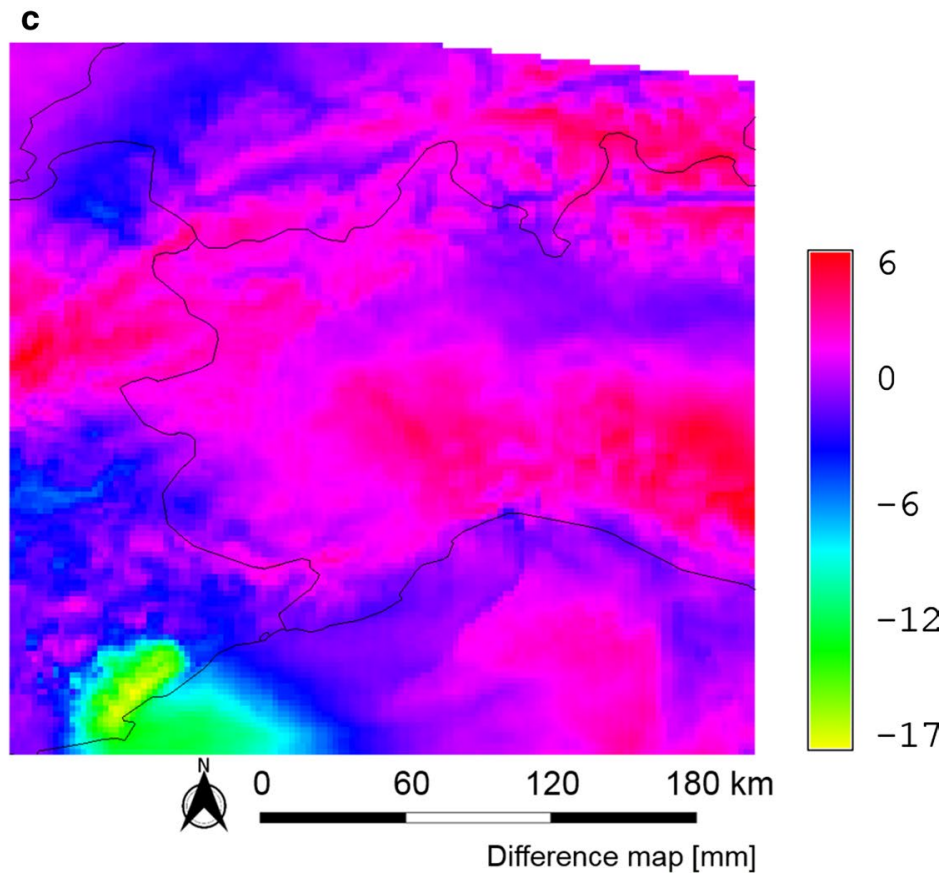

Fig. $7 \triangle P W V$ map based on the G4M procedure (a) and WRF (b). c Depicts the $\triangle P W V$ difference map (G4M-WRF). The maps refer to November 4, 2011, 10:00 UTC with respect to November 3, 2011, 02:00 UTC

produces a smooth map with not adequately enhanced HI peaks, the 1- and 3-km HI maps reproduce the $\triangle \mathrm{PWV}$ spatial variability well. Because $1-\mathrm{km}$ resolution is comparable to the spatial scales of the analyzed meteorological phenomenon, $1 \mathrm{~km}$ was determined to be the most appropriate choice.

In contrast to the $\triangle \mathrm{PWV}$ map, the HI map detects the location and timing of severe rainfall. Figure $8 \mathrm{~b}$ shows the HI map corresponding to the $\triangle \mathrm{PWV}$ map of Fig. 8a. High HI values are present only in circle 1 , where the event occurred, but not in circle 2, where no rain occurred.

At present, the $\mathrm{HI}$ represents a promising indicator for the detection of severe events in time and space. In the future, data will be collected from many rain gauges and the correlation between rainfall and HI peaks will be studied in depth, paying particular attention to the localized spatial and temporal distribution of heavy rainfall.

\section{Test case: the severe event in Genoa (Italy) on November 4, 2011}

During the morning of November 4, 2011, a stationary and self-healing storm developed over the city of Genoa, Italy, causing a huge amount of rain with intensities of up to $169 \mathrm{~mm} / \mathrm{h}$ near the city center (Vicomorasso rain gauge; ARPAL, ${ }^{18}$ 2012), which locally highly varied in space and time. In some areas of Genoa, almost 400-mm rain fell over the entire day and $\sim 300-\mathrm{mm}$ rain fell from 09:00 to 13:00 UTC. This severe meteorological event led to the flooding of the Bisagno River and its tributary Fereggiano, causing the death of six people and much damage.

Figure 11 shows the reflectivity map observed by the Bric della Croce (Turin, Italy) meteorological radar at 11:35 UTC on November 4, 2011 (ARPAL 2012). The localized distribution of intense rainfall around Genoa (circle 1 in Fig. 8) and moderate values elsewhere (e.g., circle 2 in Fig. 8, circle 3 in Fig. 16) are evident.

Figure 12 shows the hourly cumulated rain obtained from four available rain gauges near the GENO and GENU PSs and their relative positions. The localized spatial and temporal variability of the meteorological phenomenon can be observed. In contrast, the precise timing of the rain maximum is almost impossible; more intense rainfall occurs from 9:00 to 13:00 UTC, with the highest values between 11:00 and 12:00 UTC and locally different intensities.

The application of the G4M procedure to this severe meteorological event based on a posteriori and simulated near real-time approaches is presented in the following "PWV a posteriori monitoring: a low-density approach"

${ }^{18}$ https://www.arpal.gov.it/. 

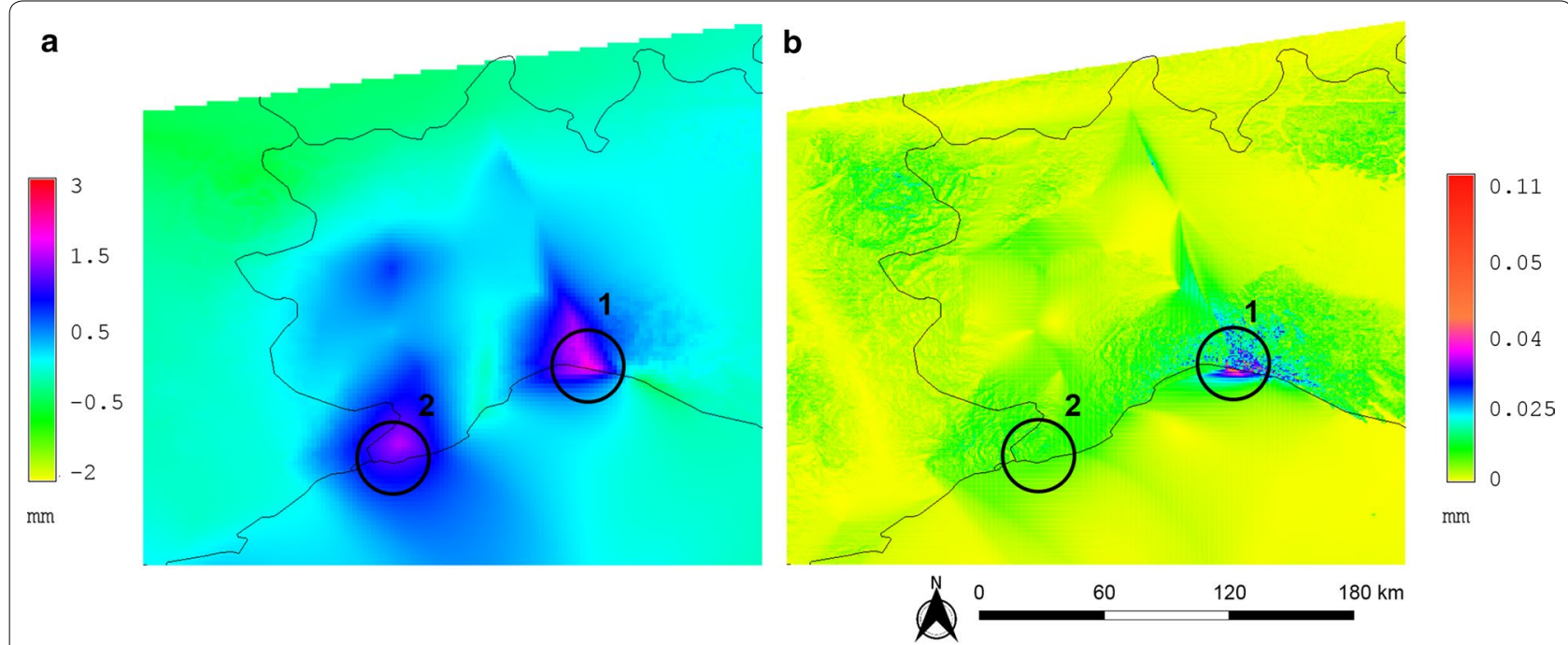

Fig. 8 Where could a severe meteorological event occur? The $\triangle P W V$ is not sufficient to determine whether a severe event may occur in circles 1 or 2 (a), whereas the HI highlights circle 1, where the severe event occurred (b). The images represent data for November 4, 2011, 10:00 UTC
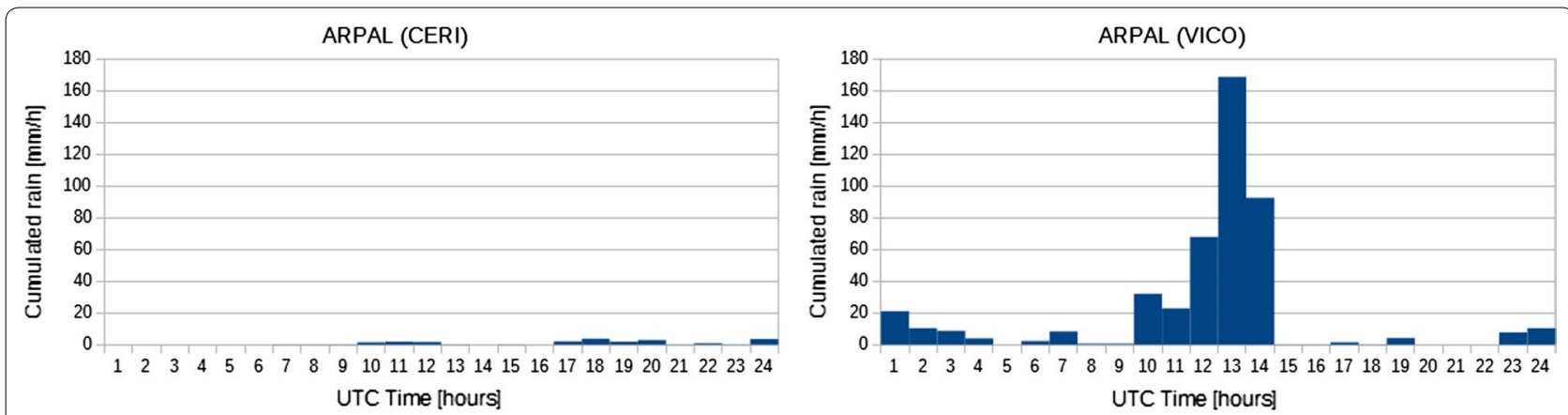

Fig. 9 Hourly cumulated rain observed on November 4, 2011, at rain gauges in circles 1 (right) and 2 (left)

and "PWV near real-time monitoring: high-density approach" sections.

\section{PWV a posteriori monitoring: a low-density approach}

To analyze the meteorological phenomenon and its evolution in space and time, $\triangle \mathrm{PWV}$ maps were produced for an area that covers approximately northwestern Italy, with particular focus on Genoa and the Liguria region. The used existing infrastructure consisted of 117 GNSS PSs with a mean spacing of $40 \mathrm{~km}$ and 35 meteorological stations with a mean spacing of approximately $150 \mathrm{~km}$ (Fig. 2). The low density of the input data led to the discretization of the computational region with a resolution of 6' (nominal WGS84 datum; 10 km).

Two-hour PWV maps were obtained from 02:00 UTC on November 3, 2011, to 00:00 UTC on November 5, 2011, using the G4M procedure. The $\triangle \mathrm{PWV}$ maps were computed to remove the orographic effect with respect to 02:00 UTC on November 3, 2011, defined as "calm" moment. Figure 13 shows the sequence of $\triangle \mathrm{PWV}$ maps for November 4, 2011, from 00:00 to 22:00 UTC. The increase in the amount of water vapor over time in the study area is evident. The Genoa event (black circle in Fig. 13) occurred between 9:00 and 13:00 UTC. Higher temporal and spatial resolutions will allow to better localize the event, as discussed in the next section.

The PWV value is useful for estimating the maximum amount of rain that can precipitate under triggering conditions. A very rough evaluation of the maximum rain intensity may be obtained by assuming that the raindrops fall with a velocity of $9 \mathrm{~m} / \mathrm{s}$ (characteristic value for the velocity of large raindrops; see Gunn and Kinzer 1949) from a typical condensation level altitude of $3000 \mathrm{~m}$; it takes $666 \mathrm{~s}$ for the rain drops to reach the ground. Assuming that the PWV remains nearly constant for $1 \mathrm{~h}$ and that all of the water vapor condenses, the following factor $k$, 

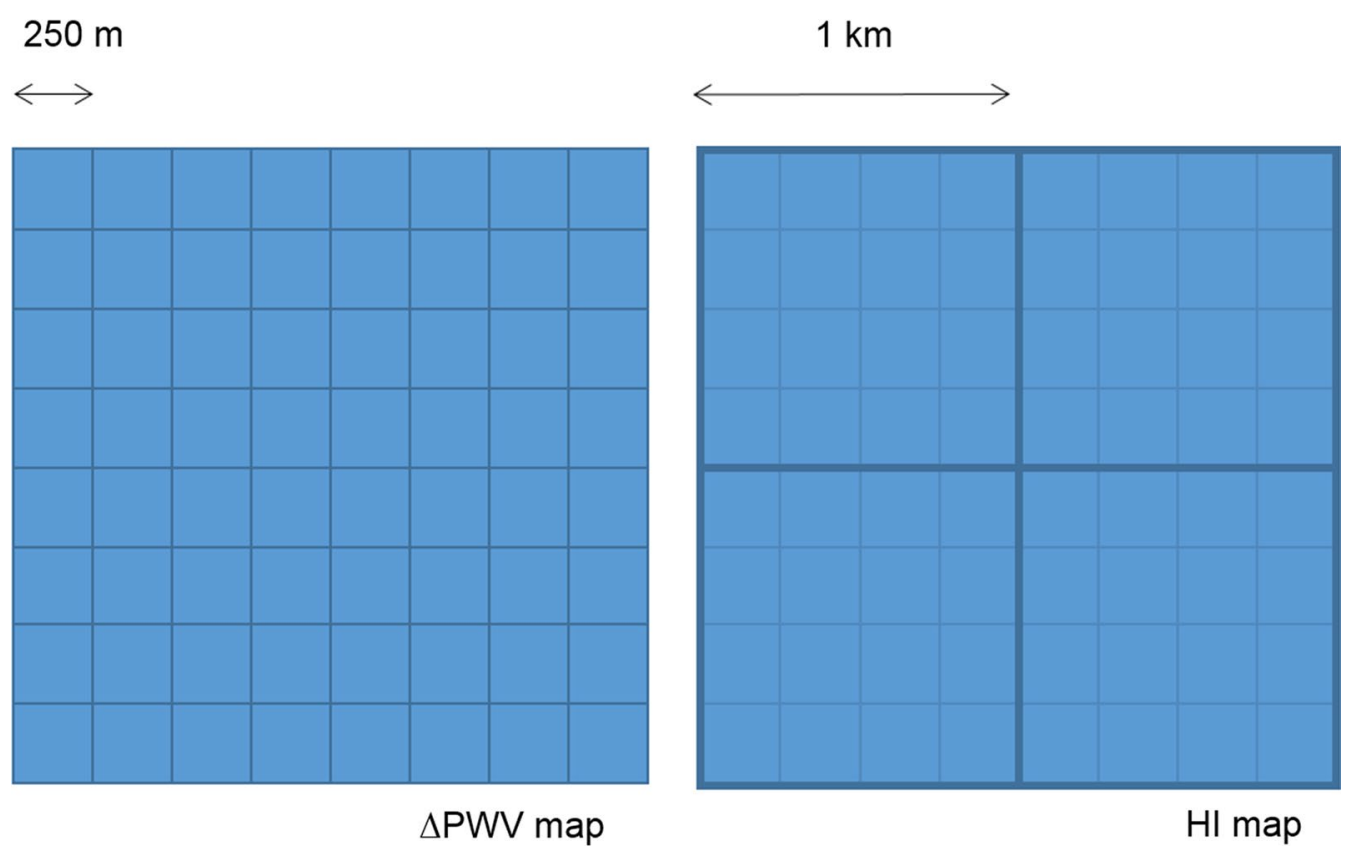

Fig. 10 Representation of the computational heterogeneity index (HI) grid with respect to the $\triangle \mathrm{PWV}$ grid

$$
k=\frac{3600}{666}=5.4
$$

can be considered as multiplying factor relating the PWV values to the maximum amount of potential rain. Thus, the PWV value of $42 \mathrm{~mm}$ obtained for 10:00 UTC on November 4, 2011 can be converted into approximately $230 \mathrm{~mm} / \mathrm{h}$ of potential rain, which contrasts the value of $75 \mathrm{~mm}$ observed from 9:00 to 10:00 UTC by the pluviometer in DICCA ${ }^{19}$ at the University of Genoa. Such a rough potential rain computation could be useful for a decision support system based on GNSS meteorology to establish risk thresholds under different rain scenarios.

\section{PWV near real-time monitoring: high-density approach}

The G4M procedure was employed to interpret meteorological events by simulating near real-time analysis. The feasibility of the procedure and its application in near real-time were evaluated, mainly focusing on required data and computational time.

Considering the limited time and space scales of severe meteorological events, typically characterized by short durations (15-30 $\mathrm{min}$ ) and extreme localization (on the order of a few kilometers), a time span of $6 \mathrm{~min}$ and spatial resolution of $250 \mathrm{~m}$ were chosen. The chosen time span is also in accordance with the computational time

\footnotetext{
${ }^{19}$ http://www.dicca.unige.it/meteo/.
}

needed to ensure a near real-time result within such a time frame.

\section{GNSS data elaboration}

Due to computational limitations of the GAMIT software, which does not allow to analyze the complete GNSS network in such a short time span, a different PSs network was considered. It consists of 15 common PSs of the three subnetworks (with a typical spacing of $\sim 1000 \mathrm{~km}), 14$ PSs of the Regione Piemonte network, 6 PSs of the Regione Liguria network, and the EUREF GENO and IGS AJAC PSs as additional stations. AJAC was primarily introduced because it contains data in the southern part of the computational region, whereas GENO was used for the comparison between the two PSs in Genoa (GENO and GENU).

Figure 14 presents the computational region and PSs.

Because of the GAMIT limitations, it is not possible to compute the ZTDs over a 24-h session in such a short time span, even with a reduced number of PSs; hence, a 4-h analysis period was considered. Based on the smaller PSs network and shorter analysis period, it was possible to obtain a ZTD estimation every $6 \mathrm{~min}$ using the GAMIT software, ensuring a near real-time ZTD solution.

With respect to possible biases introduced by these settings, the agreement between the 6-min and 2-h ZTD solutions was verified. Figure $15 \mathrm{a}$ presents the 6 -min and 2-h ZTD estimates for November 4, 2011, for the $4 \mathrm{~h}$ 


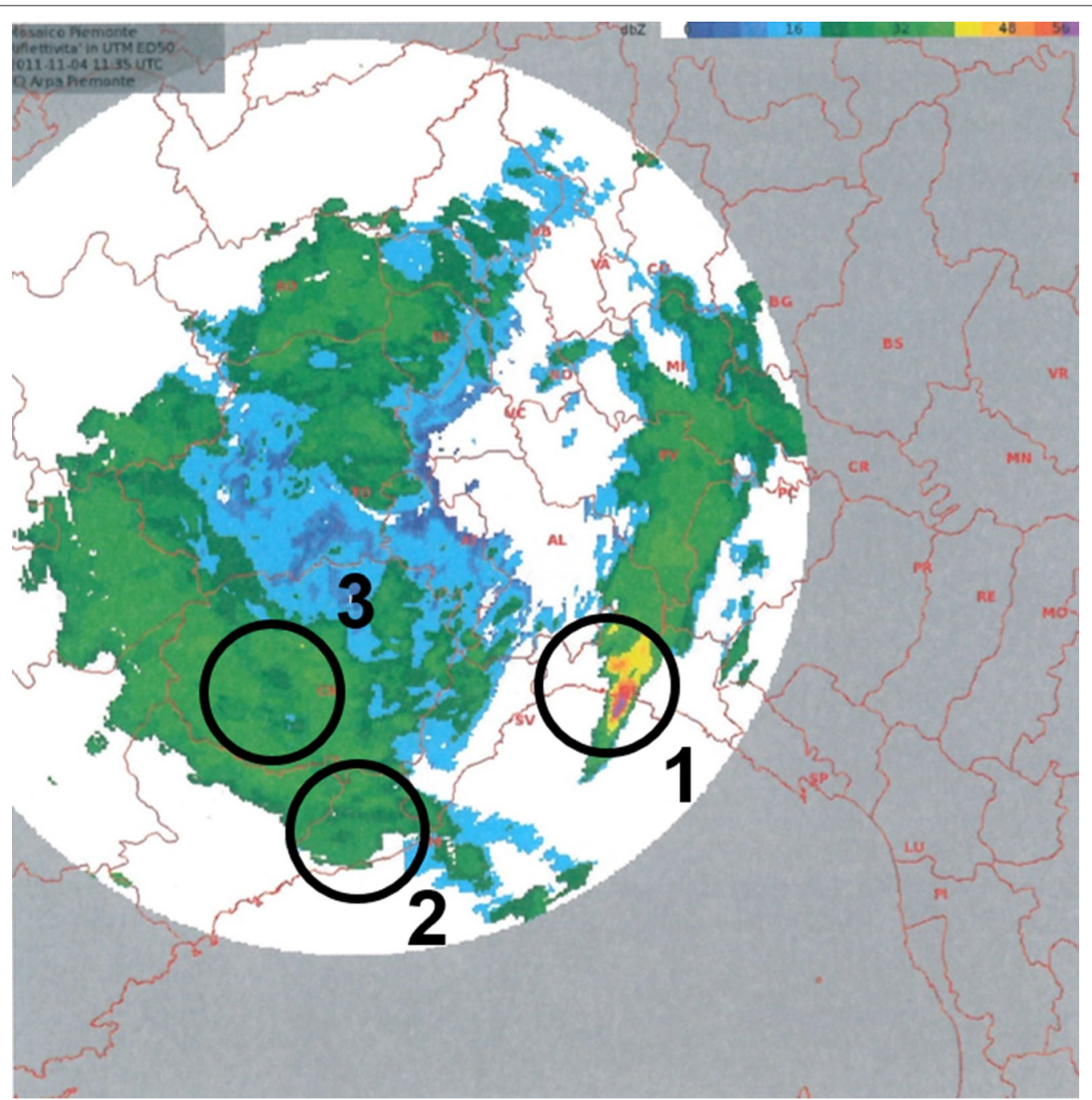

Fig. 11 Reflectivity map observed by the Bric della Croce (Turin, Italy) meteorological radar at 11:35 UTC on November 4, 2011. The localized distribution of intense rainfall around Genoa (circle 1) and moderate values elsewhere (e.g., circles 2 and 3) are evident

from 8:00 to 12:00 UTC, while Fig. 15b presents the rms estimates for the 6-min and 2-h ZTD estimations.

Slight differences in the ZTD estimates on the order of a few millimeters can be observed, while the 2-h and 6-min ZTD rms estimates show larger differences, mainly close to the start and end of the session. Hence, only the 6-min ZTD estimates for the three central hours of the session (08:00-12 UTC) were used to produce the 6-min PWV maps for the severe event that occurred in Genoa on November 4, 2011. However, the higher rms values of the 6-min analysis did not seem to affect the ZTD time evolution; thus, the procedure could be employed for near real-time applications.

\section{Pressure and temperature data}

The $P$ and $T$ networks that were used to calculate the PWV every 6 min included all stations of the NOAA archive in northwestern Italy and southeastern France that contain sub-hourly and hourly sampled data for the analyzed 4-h time span. The network geometry is shown in Fig. 2.

The $P$ and $T$ data were sampled every 6 min at each station by interpolating the observed data in time, assuming linear behavior between two consecutive datapoints.

\section{Near real-time PWV and HI maps}

The severe event in Genoa on November 4, 2011 was analyzed by applying the G4M procedure with a simulated near real-time strategy. The resolution of the 


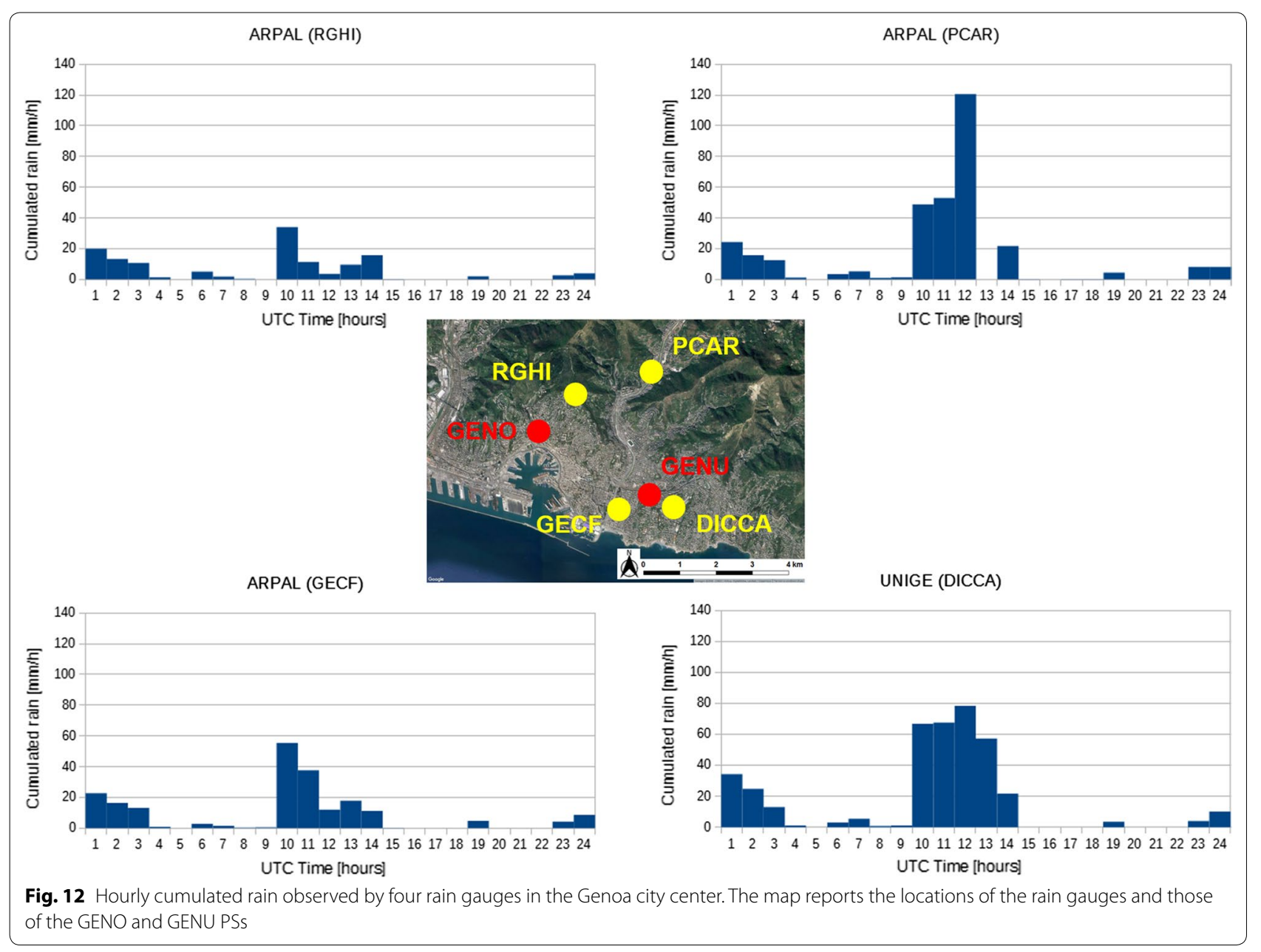

realized maps (both for meteorological parameters and for GNSS-derived data) is 8", corresponding to approximately $250 \mathrm{~m}$.

A 30-min extraction of the 6-min $\triangle \mathrm{PWV}$ maps, from 9:00 to 11:30 UTC on November 4, 2011, is presented in Fig. 16. The $\triangle \mathrm{PWV}$ maps were obtained by differentiation in time with respect to 8:30 UTC on November 4, 2011, representing relative calm conditions with respect to the rain peak. The $\triangle \mathrm{PWV}$ maps, representing the time differences of the PWV, highlight both positive and negative time differences, corresponding to an increase and decrease in the water vapor amount in the atmosphere, respectively, and help to interpret the PWV evolution. The PWV time evolution suggests an increase from 8:30 to 10:00 UTC (up to $\sim 2 \mathrm{~mm}$ for GENO and $2.5 \mathrm{~mm}$ for GENU) for Genoa (circle 1 in Fig. 16). Subsequently, a decrease is evident, which might be related to the reduction in water vapor in the atmosphere due to intense rainfall. The complete $\triangle \mathrm{PWV}$ time series (every $6 \mathrm{~min}$ ) for the two Genoa PSs, GENO, and GENU, is depicted in Fig. 17. Note the higher peak of GENU and a temporal shift in the decreasing phase of the PWV over the Genoa PSs, which may be due to the spatial proximity of GENU to the location of the most intense rainfall and the moderate precipitation observed in GENO, only $4 \mathrm{~km}$ away (Fig. 12).

In addition to the $\triangle \mathrm{PWV}$ peak of Genoa, another peak with analogous values is evident in the area around Mondovì (circle 3 in Fig. 16), where an intense meteorological event might occur.

To better detect and interpret severe rainfall, HI maps were produced with a spatial resolution of $1 \mathrm{~km}$ and a time resolution of 6 min from 8:30 to 11:30 UTC on November 4, 2011. A 30-min extraction from 9:00 to 11:30 UTC is presented in Fig. 18. As expected, the intense meteorological event can be localized with the $\mathrm{HI}$, in time and space, assuming values close to zero for the whole area, except for Genoa, where the event occurred (red circle in Fig. 18). In contrast, the $\triangle \mathrm{PWV}$ peak observed in circle 3 in Fig. 16 does not correspond to a high HI value in Fig. 18, which was expected based on the moderate radar reflectivity in that area (Fig. 11). 

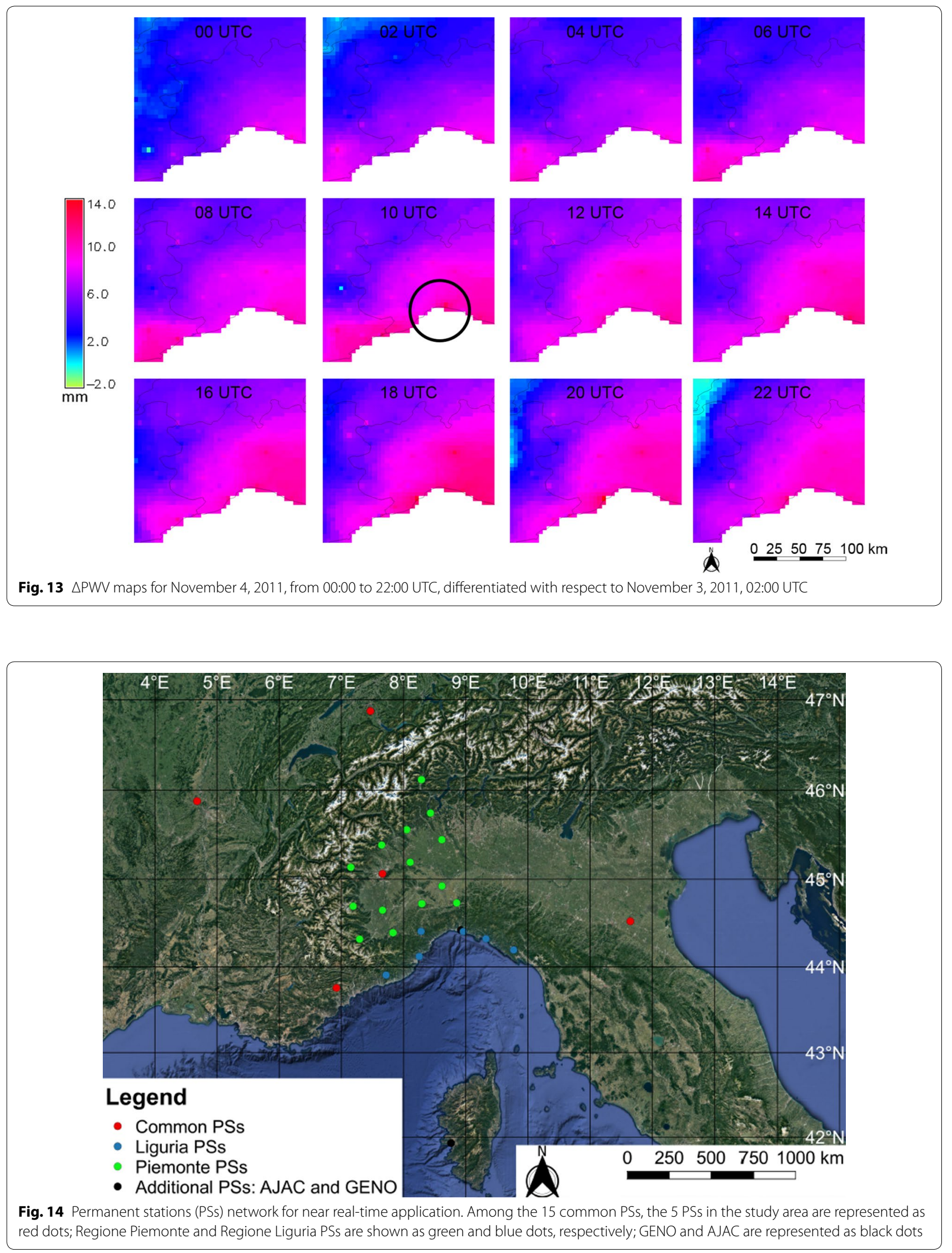


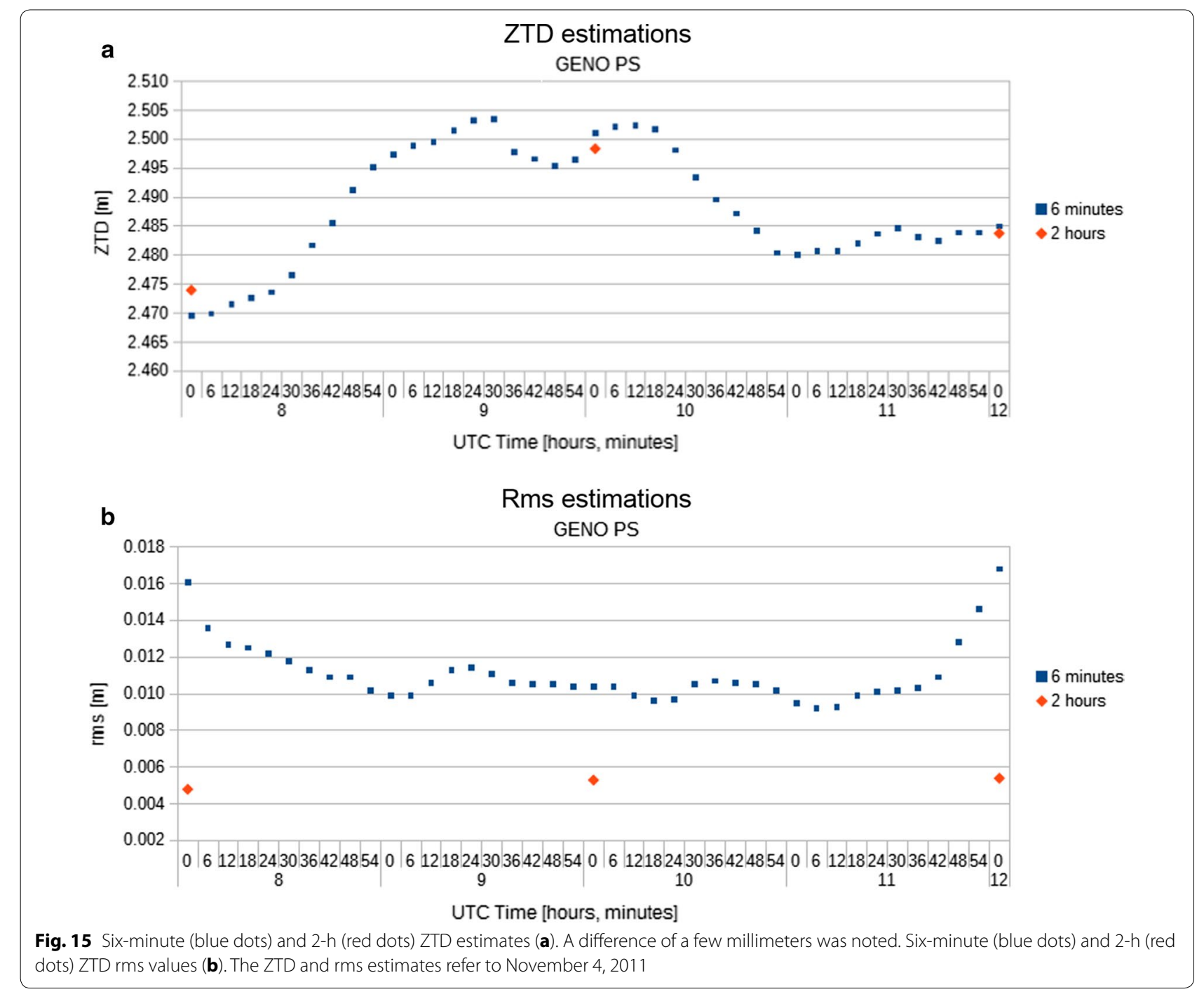

Figure 19 reports the 6-min evolution of the $\mathrm{HI}$ in the area around Genoa from 10:42 to 11:12 UTC, showing an increase until 11:00 UTC (HI maximum of $0.11 \mathrm{~mm}$ ) and a subsequent decrease. The timings of the highest HI values (at 11:00 UTC) in the analyzed time window (8:30-11:30 UTC) are in accordance with the highest rain values. The HI seems to predict several tens of minutes of the maximum observed rain, located between 11:00 and 12:00 UTC in hourly histograms, and ARPAL, the regional agency for environmental protection, describes the event with the radar image of 11:35 UTC (ARPAL 2012). The HI evolution represents the evolution of the heterogeneity, that is, spatial $\triangle \mathrm{PWV}$ inhomogeneity (corresponding to a localized increase or decrease in PWV with respect to the reference epoch). The locally strong spatial variation in $\triangle \mathrm{PWV}$ seems to be correlated to the intense meteorological event considered in this study.
The correspondence between $\mathrm{HI}$ and the rain peaks will be studied in detail in the near future.

\section{Conclusions and future perspectives}

The present work focuses on the possibility of obtaining 2D PWV maps using the GNSS and $P$ and $T$ data from existing infrastructure for a large and orographically complex area, as a contribution to GNSS meteorology. Based on Bevis et al. (1992), a procedure called G4M has been conceived by the authors to produce 2D PWV maps with high spatiotemporal resolution (up to $250 \mathrm{~m}$ for PWV and $1 \mathrm{~km}$ for HI maps; $6 \mathrm{~min}$ ).

The procedure was applied to an area approximately covering northwestern Italy, with altitude ranges from sea level to $>4500 \mathrm{~m}$, to study a severe meteorological event that occurred in Genoa on November 4, 2011. The input data of the procedure are ZTD estimates and $P$ and 


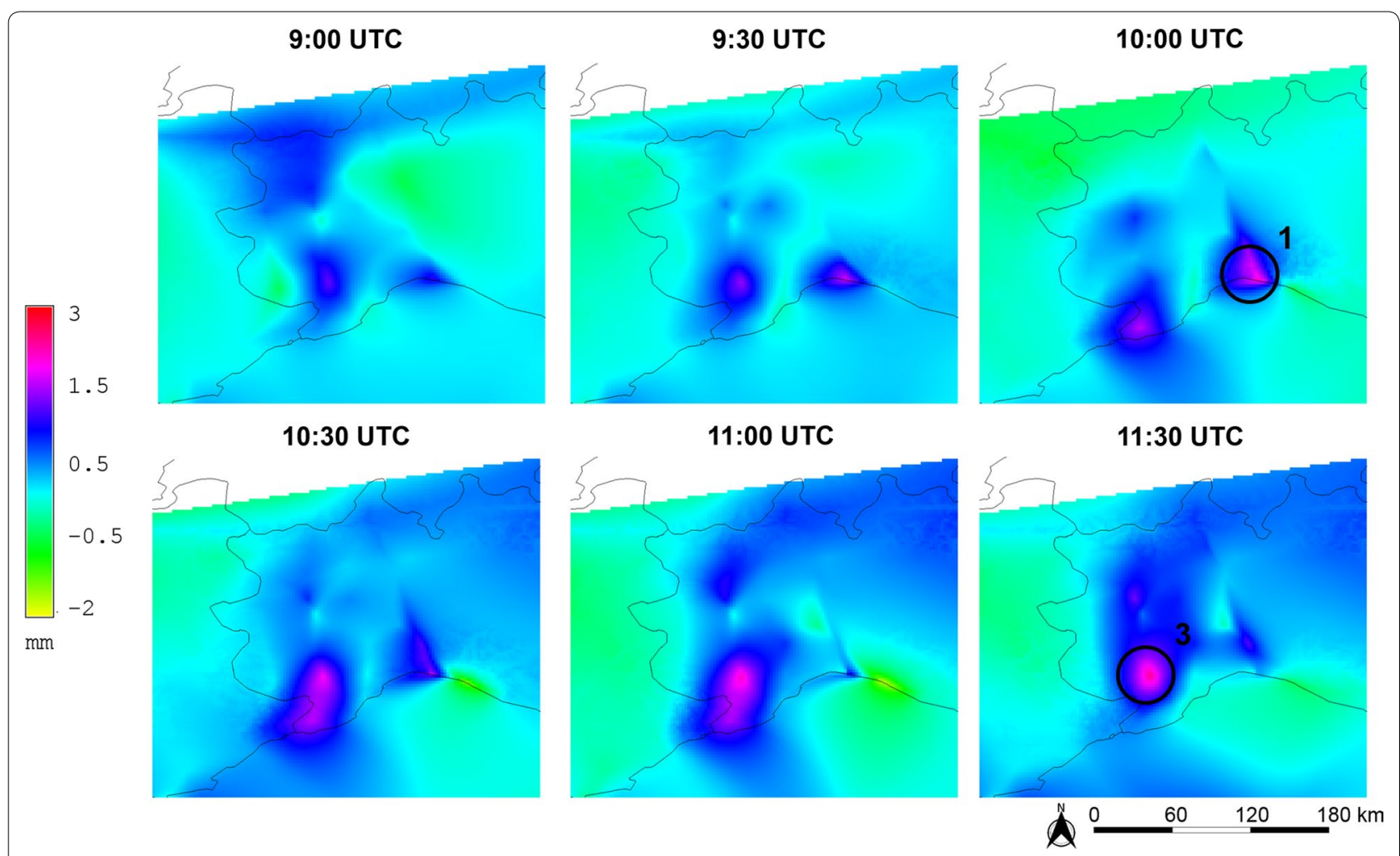

Fig. 16 30-minute extraction from the 6-minute $\triangle P W V$ maps for the severe event on November 4, 2011, differentiated with respect to November 4, 2011, 08:30 UTC

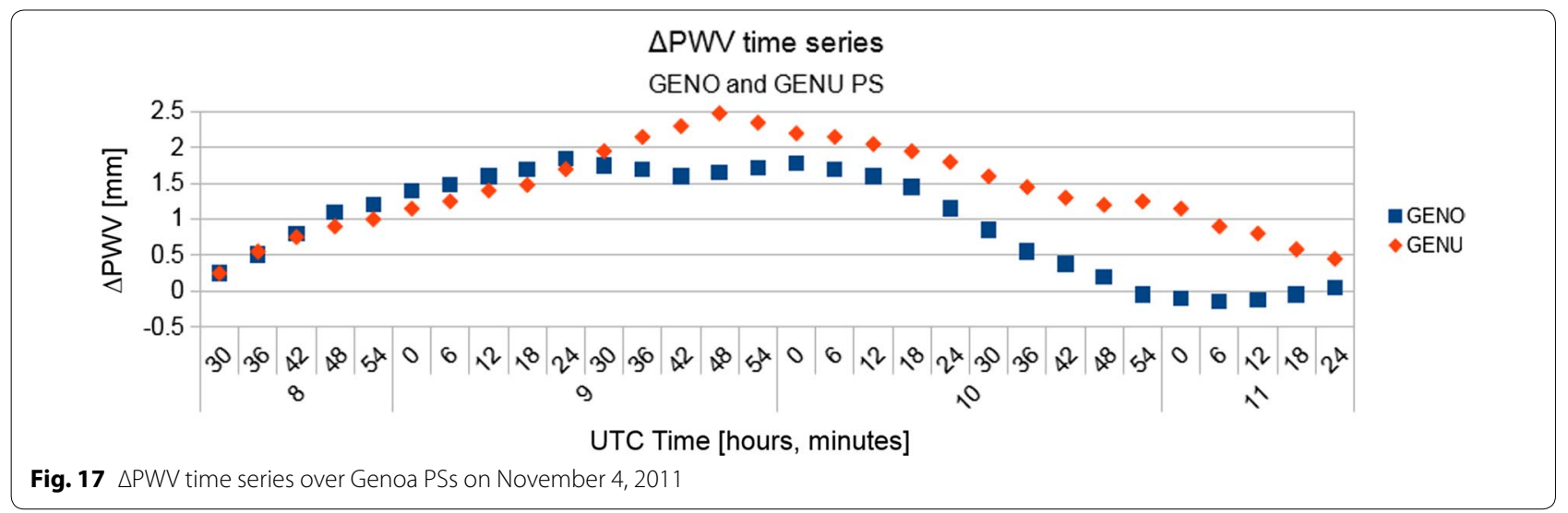

$T$ observations from international measuring stations at different discrete points, with a mean spacing of 40 and $150 \mathrm{~km}$, respectively. Note that, even if higher-density regional networks could improve the results, the procedure can be applied to any international network and therefore to any area in the world.

The ZTD values were estimated using the GAMIT/ GLOBK software applied to a "local network" composed of GNSS PSs of different international, national, and regional networks in the French-Italian border region. A dedicated DB hosts the 2-h ZTD estimates for the PSs from 1998 to 2012; the DB will soon be updated to December 2015.

The strength and originality of the G4M procedure are based on the use of existing infrastructure, independence from meteorological models, possibility of automation, high adaptability to different network configurations, and ability to produce high-resolution 2D PWV maps, even 


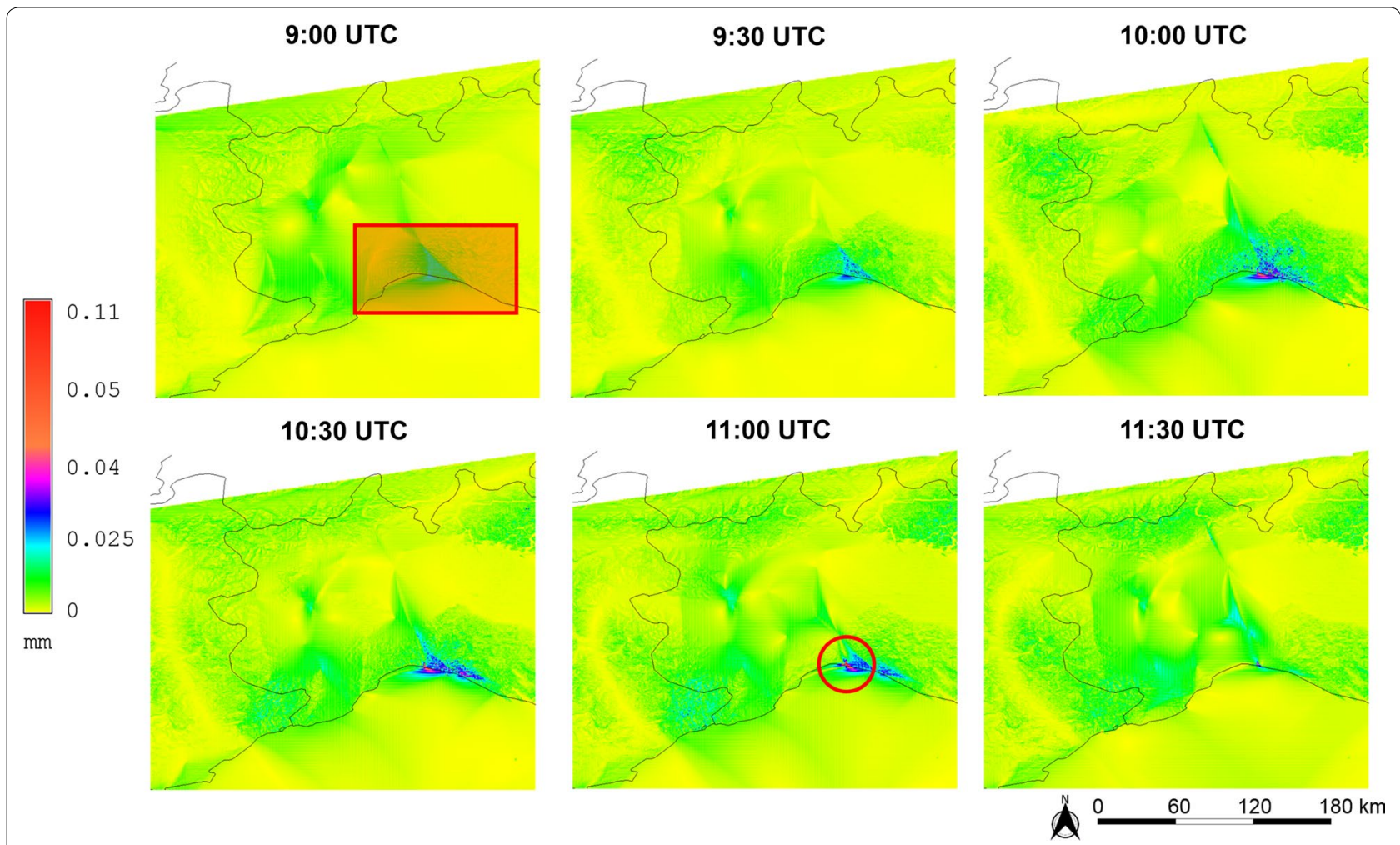

Fig. 18 30-minute extraction from the 6-min HI maps for the severe event on November 4, 2011. The red rectangle highlights the zoomed area represented in Fig. 19. The red circle reports the time of the most elevated $\mathrm{HI}$ values

from sparse input data. In fact, combined with the high resolution and wide computational region, the G4M produces 2D PWV maps based on a simplified mathematical model that was established by the authors, despite difficulties due to the sparse distribution of $P, T$, and ZTD data.

A validation has been carried out both in $1 \mathrm{D}$ and $2 \mathrm{D}$ : study of the PWV time series including PSs at different altitudes, evaluation of the PWV behavior along a section crossing complex topography, and computation of difference maps. The PWV 2D maps generated by the G4M and those originating from WRF meteorological simulations were compared. The differences between the two models do not influence the interpretation of the evolution in time; hence, the procedure can be considered effective. The key role of orography emerged, which can be roughly removed by introducing the $\triangle \mathrm{PWV}$ map, representing the differentiation of the PWV in time with respect to a calm moment. The observation of different PWV values over time provides the spatial and temporal evolution of the PWV, allowing for easier monitoring of the atmosphere.

In fact, the comparison between the PWV maps from the G4M and those from WRF shows differences ranging from -42 to $119 \mathrm{~mm}$ in the analyzed area, while the $\triangle \mathrm{PWV}$ difference map ranges from -17 to $6 \mathrm{~mm}$. The same reduction in the orographic effect has been noticed along a section crossing high-altitude areas.

The new HI index makes the localization of severe meteorological events in time and space possible; it accounts for the spatial variability of $\triangle \mathrm{PWV}$. It allows to discriminate between locations and times characterized by high $\triangle \mathrm{PWV}$ values based on spatial $\triangle \mathrm{PWV}$ heterogeneity, which seems to be correlated with the intense meteorological event considered in this study.

The G4M procedure has been applied both to a posteriori and simulated near real-time strategies using 2-h and 6-min ZTD, $P$, and $T$ data. The simulated near realtime strategy and the analysis of the $\mathrm{HI}$ evolution during the event seem to be promising for a future early warning system based on G4M maps. In fact, because the entire G4M procedure is independent of meteorological models, it could be innovatively integrated in these models, supporting now-casting.

Systematic application of the innovative G4M procedure to different case studies (intense and moderate events, lacking/false meteorological alerts) to statistically evaluate the reliability of the $\mathrm{HI}$ and its performance is planned for the future. Moreover, the relationship between the $\mathrm{HI}$ and rain peaks will be studied in depth. 


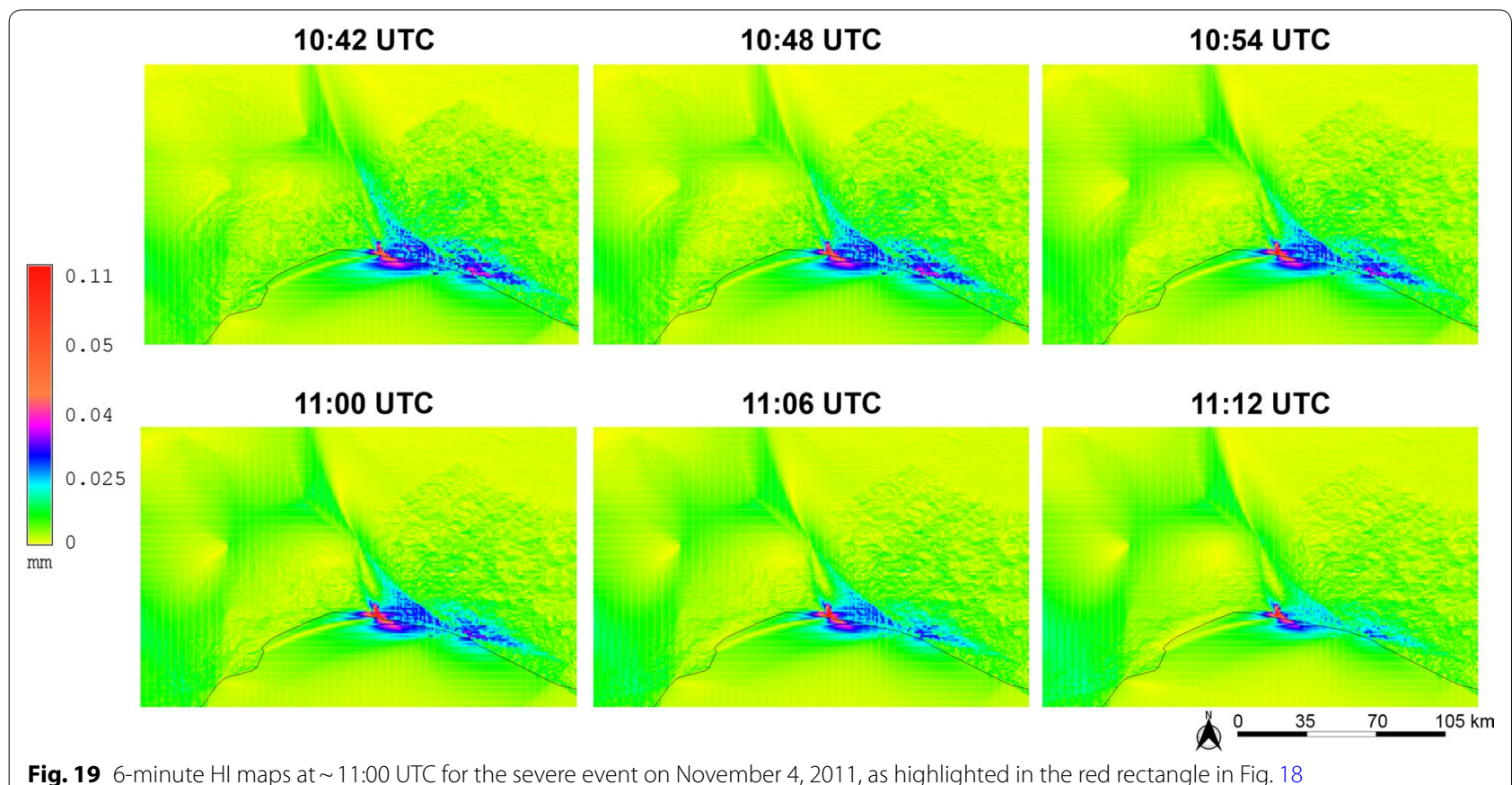

The benefits of using a higher-density meteorological station network will also be investigated based on an agreement with ARPAL, the regional meteorological agency, to test and eventually improve the whole G4M procedure.

\section{Abbreviations \\ AGNES: Automated GNSS Network for Switzerland; ARPAL: Agenzia Regionale per la Protezione dell'Ambiente Ligure; ASTER: Advanced Spaceborne Thermal Emission and Reflection Radiometer; DB: database; DTM: digital terrain model; DICCA: Department of Civil, Chemical and Environmental Engineering; ECMWF: European Centre for Medium-Range Weather Forecasts; EUREF: Euro- pean Reference Frame; G4M: GNSS for Meteorology; GAIN: Geodetic Alpine Integrated Network; GDEM: Global Digital Elevation Model; GEODAF: Geodetic Data Archiving Facility; GEONET: GNSS Earth Observation Network System; GIS: geographic information system; GMF: global mapping function; GNSS: Global navigation satellite system; GRASS: Geographic Resources Analysis Support System; GPT: global pressure and temperature; HI: heterogeneity index; IDW: inverse distance weighted; IGS: International GNSS Service; NOAA: National Oceanic and Atmospheric Administration; P: pressure; PS(s): permanent station(s); PWV: precipitable water vapor; RENAG: RÉseau NAtional GNSS Permanent; RGP: Réseau GNSS Permanent; RING: Rete Integrata Nazionale GPS; RST: regularized spline with tension; T: temperature; TIN: triangulated irregular network; WGS84: World Geodetic System 1984; WRF: Weather Research and Forecasting; ZHD: zenith hydrostatic delay; ZTD: zenith total delay; ZWD: zenith wet delay.}

\section{Authors' contributions}

The present work originates from IF's Ph.D. thesis, which was supervised by BF and DS. All authors equally contributed to the writing of this paper. All authors read and approved the final manuscript.

\section{Acknowledgements}

The authors wish to thank Dr. Andrea Walpersdorf for her fundamental competencies with respect to the realization of the RENAG database; Prof. Toshitaka Tsuda for his suggestions and inspiration regarding the heterogeneity index; and Prof. Andrea Mazzino, Dr. Federico Cassola, and Dr. Francesco Ferrari for sharing meteorological simulation data and their support with the WRF model. The present work is a contribute to the Troposphere Working Group of the IGS (International GNSS Service) from one of the authors, as a member.

\section{Competing interests}

The authors declare that they have no competing interests.

\section{Ethics approval and consent to participate}

Not applicable.

\section{Publisher's Note}

Springer Nature remains neutral with regard to jurisdictional claims in published maps and institutional affiliations.

\section{Received: 24 August 2017 Accepted: 24 March 2018}

Published online: 03 April 2018

\section{References}

Altamimi Z, Collilieux X, Métivier L (2011) ITRF2008: an improved solution of the international terrestrial reference frame. J Geod 85(8):457-473

ARPAL (2012) Genoa November 4-9, 2011 meteo-hydrological event report. Quaderni ARPAL, n.2. (in Italian). https://www.arpal.gov.it/images/stories/meteo/Documenti_sito/QuadernoArpalGenovaSettembre_WEB.pdf. Accessed 23 Feb 2018

Basili P, Bonafoni S, Ferrara R, Ciotti P, Fionda E, Betti B, Prini R, Tornatore V, Crespi M, Di Paola S, Baiocchi V, Radicioni F (2003) Assessment of precipitable water vapor by use of a local GPS network and microwave ground-based radiometer. In: 11 th International conference on antennas and propagation, 2001, pp 72-76

Bennitt GV, Jupp A (2012) Operational assimilation of GPS zenith total delay observations into the met office numerical weather prediction models. Mon Weather Rev 140:2706-2719

Bevis M, Businger S, Herring T, Rocken C, Anthes R, Ware R (1992) GPS meteorology - remote sensing of atmospheric water vapor using the global positioning system. J Geophys Res 97:15787-15801 
Bock O, Bouin MN, Doerflinger E, Collard P, Masson F, Meynadier R, Nahmani S, Koité M, Balawan KGL, Didé F, Ouedraogo D, Pokperlaar S, Ngamini JB, Lafore JP, Janicot S, Guichard F, Nuret M (2008) West African Monsoon observed with ground-based GPS receivers during African monsoon multidisciplinary analysis (AMMA). J Geophys Res 113:D21105

Boehm J, Niell AE, Tregoning P, Schuh H (2006) Global mapping function (GMF): a new empirical mapping function based on numerical weather model data. Geophys Res Lett 33:L07304

Boehm J, Heinkelmann R, Schuh H (2007) Short note: a global model of pressure and temperature for geodetic applications. J Geod 81 (6-8):679-683

Boniface K, Ducrocq V, Jaubert G, Yan X, Brousseau P, Masson F, Champollion C, Chéry J, Doerflinger E (2009) Impact of high-resolution data assimilation of GPS zenith delay on Mediterranean heavy rainfall forecasting. Ann Geophys 27(7):2739-2753

Bouma HR, Stoew B (2001) GPS observations of daily variations in the atmospheric water vapor content. Phys Chem Earth Part A Solid Earth Geod 26:389-392

Cassola F, Ferrari F, Mazzino A (2015) Numerical simulations of Mediterranean heavy precipitation events with the WRF model: a verification exercise using different approaches. Atmos Res 164-165:210-225

De Pondeca MSFV, Zou X (2001) A case study of the variational assimilation of GPS zenith delay observations into a mesoscale model. J Appl Meteorol 40:1559-1576

Environmental Modeling Center (2003) The GFS atmospheric model. NCEP Office Note 442, National Oceanic and Atmospheric Administration

Ferrando I, De Rosa P, Federici B, Sguerso D (2016) Spatial interpolation techniques for a near real-time mapping of pressure and temperature data. PeerJ Prepr. https://doi.org/10.7287/peerj.preprints.2223v2

Ferrando I, Federici B, Sguerso D (2017) Zenith total delay interpolation to support GNSS monitoring of potential precipitations. GEAM Geoingegneria Ambientale e Mineraria 4(2):85-90

GRASS Development Team (2010) Geographic resources analysis support system (GRASS) software, Version 6.4.0. Open Source Geospatial Foundation http://grass.osgeo.org. Accessed 23 Aug 2017

Gunn R, Kinzer GD (1949) The terminal velocity of fall for water droplets in stagnant air. J Meteorol 6(4):243-248

Herring TA, King RW, McClusky SC (2010) GAMIT reference manual—release 10.4. Department of Earth, Atmospheric, and Planetary Sciences, Massachusetts Institute of Technology, USA

Herring TA, King RW, McClusky SC (2015) GAMIT reference manual_-release 10.6. Department of Earth, Atmospheric, and Planetary Sciences, Massachusetts Institute of Technology, USA

Inoue HY, Inoue T (2007) Characteristics of the water-vapor field over the Kanto district associated with summer thunderstorm activities. Sci Online Lett Atmos 3:101-104

Lyard F, Lefevre F, Letellier T, Francis O (2006) Modelling the global ocean tides: a modern insight from FES2004. Ocean Dyn 56(5-6):394-415

Oigawa M, Realini E, Tsuda T (2015) Study of water vapor variations associated with meso- $\gamma$ scale convection: comparison between GNSS and nonhydrostatic model data. Sci Online Lett Atmos 2:27-30

Pacione R, Vespe F (2003) GPS Zenith total delay estimation in the mediterranean area for climatological and meteorological applications. J Atmos Ocean Technol 20:1034
Realini E, Tsuda T, Sato K, Oigawa M, Iwaki Y (2012) Analysis of the temporal and spatial variability of the wet troposphere at a local scale by high-rate PPP using a dense GNSS network. In: Proceedings of the 25th international technical meeting of the satellite division of the institute of navigation (ION GNSS 2012), Nashville, TN, pp 3406-3412

Rocken C, Van Hove T, Ware R (1997) Near real-time GPS sensing of atmospheric water vapor. Geophys Res Lett. https://doi.org/10.1029/97GL03312

Sato K, Realini E, Tsuda T, Oigawa M, Iwaki Y, Shoji Y, Seko H (2013) A highresolution, precipitable water vapor monitoring system using a dense network of GNSS receivers. J Disaster Res 8(1):37-47

Schmid R, Steigenberger P, Gendt G, Ge M, Rothacher M (2007) Generation of a consistent absolute phase center correction model for GPS receiver and satellite antennas. J Geod 81:781-798

Seko H, Shoji Y, Fujibe F (2007) Evolution and air flow structure of a Kanto thunderstorm on 21 July 1999 (the Nerima Heavy Rainfall Event). J Meteorol Soc Jpn 85:455-477

Sguerso D, Labbouz L, Walpersdorf A (2013) 14 Years of GPS tropospheric delays in the French-Italian border region: a database for meteorological and climatological analyses. The international archives of the photogrammetry, remote sensing and spatial information sciences, XL-5/W3, pp 7-14

Sguerso D, Labbouz L, Walpersdorf A (2016) 14 years of GPS tropospheric delays in the French-Italian border region: comparisons and first application in a case study. Appl Geomat 8(1):1-13

Shoji Y (2009) A study of near real-time water vapor analysis using a nationwide dense GPS network of Japan. J Meteorol Soc Jpn 87:1-18

Shoji Y, Nakamura H, Aonashi K, Ichiki A, Seko H (2000) Semi-diurnal and diurnal variation of errors in GPS precipitable water vapor at Tsukuba, Japan, caused by site displacement due to ocean tidal loading. Earth Planets Space 52:685-690. https://doi.org/10.1186/BF03352264

Shoji Y, Nakamura H, Iwabuchi T, Aonashi K, Seko H, Mishima K, Itagaki A, Ichikawa R, Ohtani R (2004) Tsukuba GPS dense net campaign observation: Improvement in GPS analysis of slant path delay by stacking one-way postfit phase residuals. J Meteorol Soc Jpn 82:301-314

Tregoning P, Van Dam T (2005) Atmospheric pressure loading corrections applied to GPS data at the observation level. Geophys Res Lett 32:L22310

Tsuda T, Sato K, Realini E, Oigawa M, Iwaki Y, Shoji Y, Seko H (2013) A real-time monitoring system of precipitable water vapor (PWV) using a dense GNSS receiver network. J Disaster Res 8(1):155-156

Yao Y, Xu C, Shi J, Cao N, Zhang B, Yang J (2015) ITG: a new global GNSS tropospheric correction model. Sci Rep 5:10273. https://doi.org/10.1038/ srep10273

Zhang C, Kuo Y, Dai L, Chu Y, Braun J, Zhang J, Li Q, Chen M (2008) The design and application of network of ground-based GPS water vapor monitoring stations to improve precipitation prediction in the Greater Beijing metropolitan area. Int Arch Photogramm Remote Sens Spat Inf Sci 37:517-522

\section{Submit your manuscript to a SpringerOpen ${ }^{\circ}$ journal and benefit from:}

- Convenient online submission

- Rigorous peer review

- Open access: articles freely available online

- High visibility within the field

- Retaining the copyright to your article

Submit your next manuscript at $\boldsymbol{\Delta}$ springeropen.com 